\title{
Annual Technology Baseline: The 2021 Electricity Update
}

Laura Vimmerstedt, Sertaç Akar, Brian Mirletz, Dana Stright, Chad Augustine, Philipp Beiter, Stuart Cohen, Wesley Cole, Patrick Duffy, David Feldman, Parthiv Kurup, Caitlin Murphy, Greg Rhodes, Anna Schleifer, Tyler Stehly (National Renewable Energy Laboratory) Debo Oladosu (Oak Ridge National Laboratory) Jeffrey Hoffmann (U.S. Department of Energy, Office of Fossil Energy) July 19, 2021 


\section{Agenda}

- Why the ATB?

- ATB Project Overview

- Technology-Specific Highlights

- Financial Cases and Methods

- Questions and Comments 


\section{Why the ATB?}

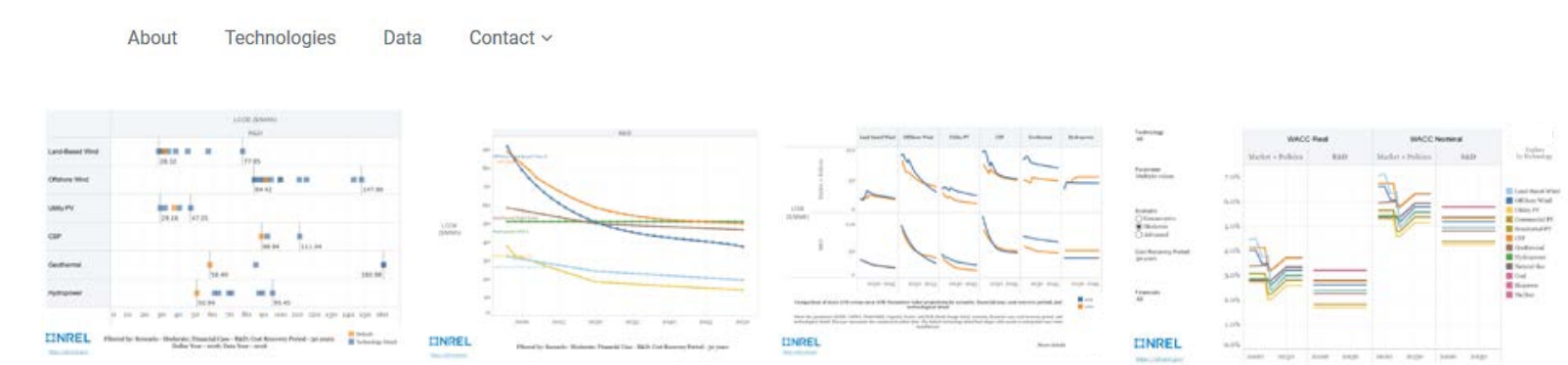

- Ever-changing technologies result in conflicting reports of technology progress based on inconsistent-and often opaque-assumptions.

- A single data set is needed to credibly and transparently assess the evolving state of energy technologies in the United States.

- The ATB enables understanding of technology cost and performance across energy sectors and thus informs electric sector analysis nationwide. 
ATB Project Overview 


\section{The ATB targets analytic transparency and consistency.}

Objective: develop and publish renewable energy technology cost and performance scenarios that are credible, comparable, and transparent, and reflect potential technology advancement

EEREa Analysis Consistency

- Ensure consistent assumptions across technologies

- Provide comparability across EERE/national laboratory projects and publications

\section{Third-Party Analysis}

- Provide access to assumptions

- Leverage national laboratory expertise 
The ATB anchors key DOE and national lab analyses.

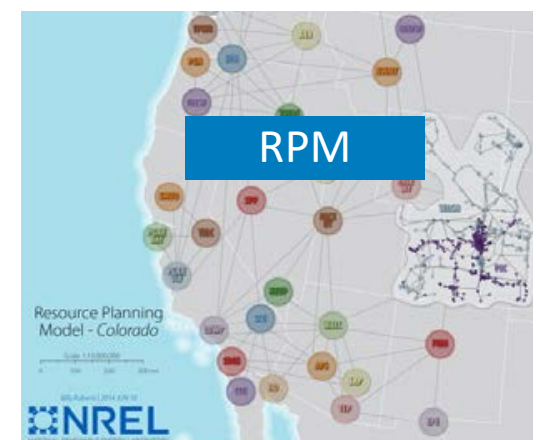

Resource Planning Model

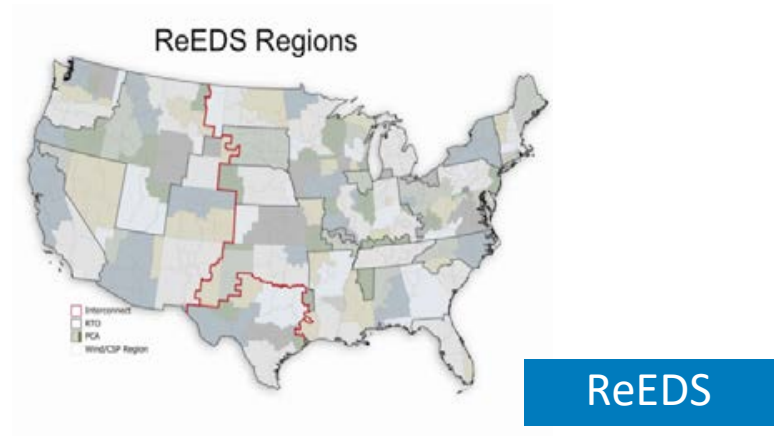

Regional Energy Deployment System

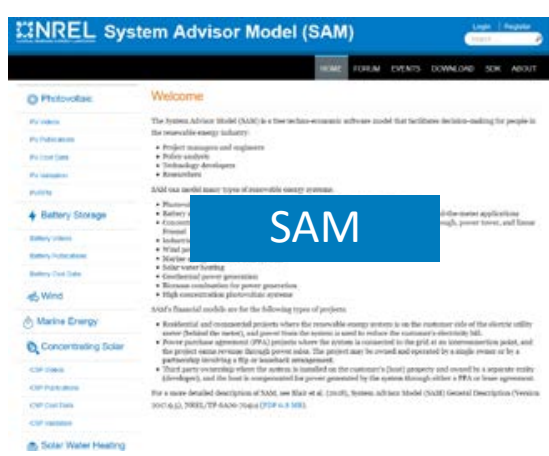

System Advisor Model

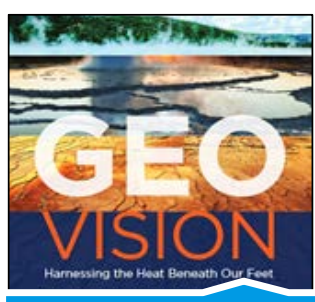

Geothermal Vision

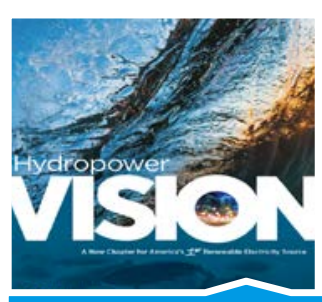

Hydropower Vision
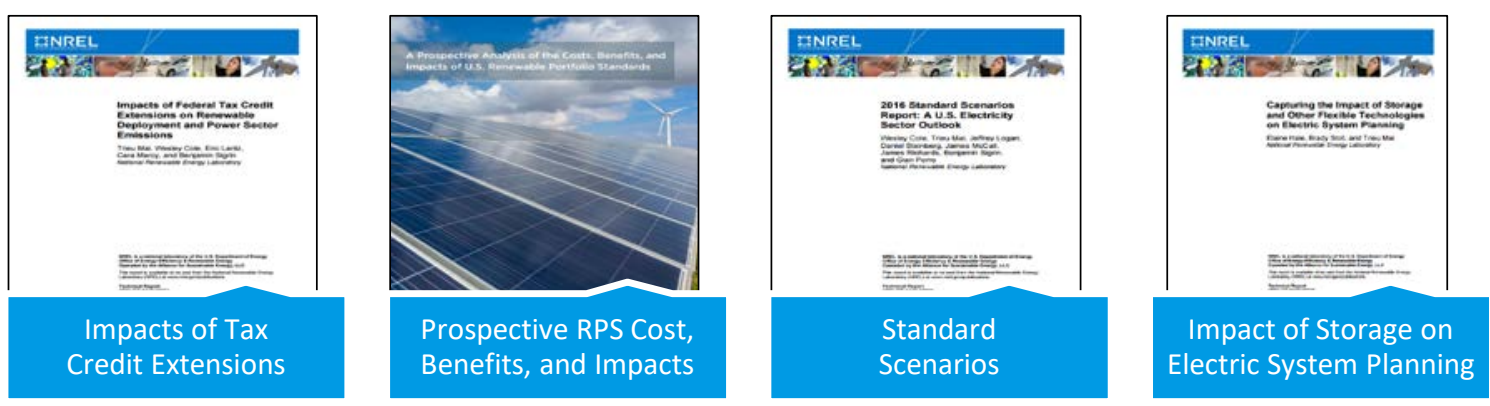


\section{Now in its seventh year, the ATB is frequently used by planners, academics, analysts, and others.}

\section{Federal Agencies}

(Bureau of Land Management, U.S. Department of Energy and labs, U.S.

Environmental Protection Agency)

\section{Consultants}

(Rhodium Group, Navigant, M.J. Bradley \& Associates, Analysis Group)

\section{Grid Operators}

(North American Electric Reliability Corporation,

Midcontinent Independent System Operator,

Pennsylvania-New Jersey-Maryland

Interconnection, New York Independent System Operator)

\section{Nonprofits}

(Resources for the Future, Environmental Defense Fund, Union of Concerned Scientists)

\section{Utilities}

(Hawaii Electric Company, Dominion Energy)

Academia

(Stanford University, University of Maryland, University of Texas, Duke University)
State Energy Offices

(Hawaii, Michigan)

\section{International}

(Chilean Ministry of Energy, Global Carbon Capture and Storage Institute, Institute, Canadian Institute for Integrated Energy Systems)
Media (Utility Dive) 


\section{Annual Technology Baseline}

Cost and performance assumptions for renewable and conventional technologies

\section{Standard Scenarios}

Ensemble of future scenarios of the U.S. electric power sector 


\section{The ATB includes a suite of products.}

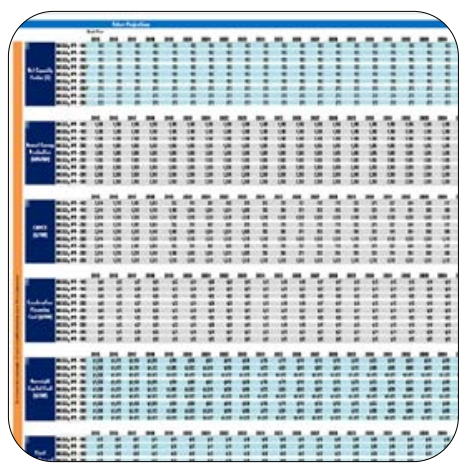

\section{Spreadsheet}

- Calculations

- Cost and performance projections, 2019-2050

- Capacity factor

- Operation and maintenance (O\&M) costs

- Capital expenditures (CAPEX)

- Financing assumptions

- Levelized cost of energy (LCOE)

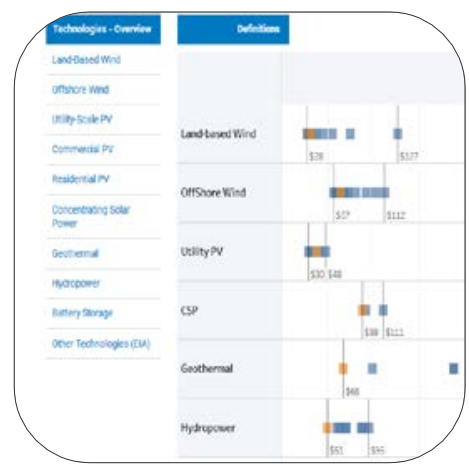

\section{Web App}

- atb.nrel.gov

- User guidance

- Additional analyses

- Methodologies

- Interactive charts

- Historical trends and comparison to other projections (e.g., EIA)

\section{Interactive Charts}

Tableau Workbook

\section{Formatted Data}

- Summary of selected data (no calculations)

- Interactive charts

- Visual exploration

- Cost and performance projections, 2019-2050

- Capacity factor

- O\&M costs

- CAPEX

- Financing assumptions

- LCOE

- Structured format

\section{WNREL}

2020 Annual Technology Baseline

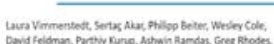

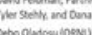
neraseoso

\section{PowerPoint}

- Webinar presentation

- Summary presentation

\section{API}

- Data published in Open Energy Data Initiative

- Programmatic access through AWS-S3 


\section{The ATB provides cost and performance data.}

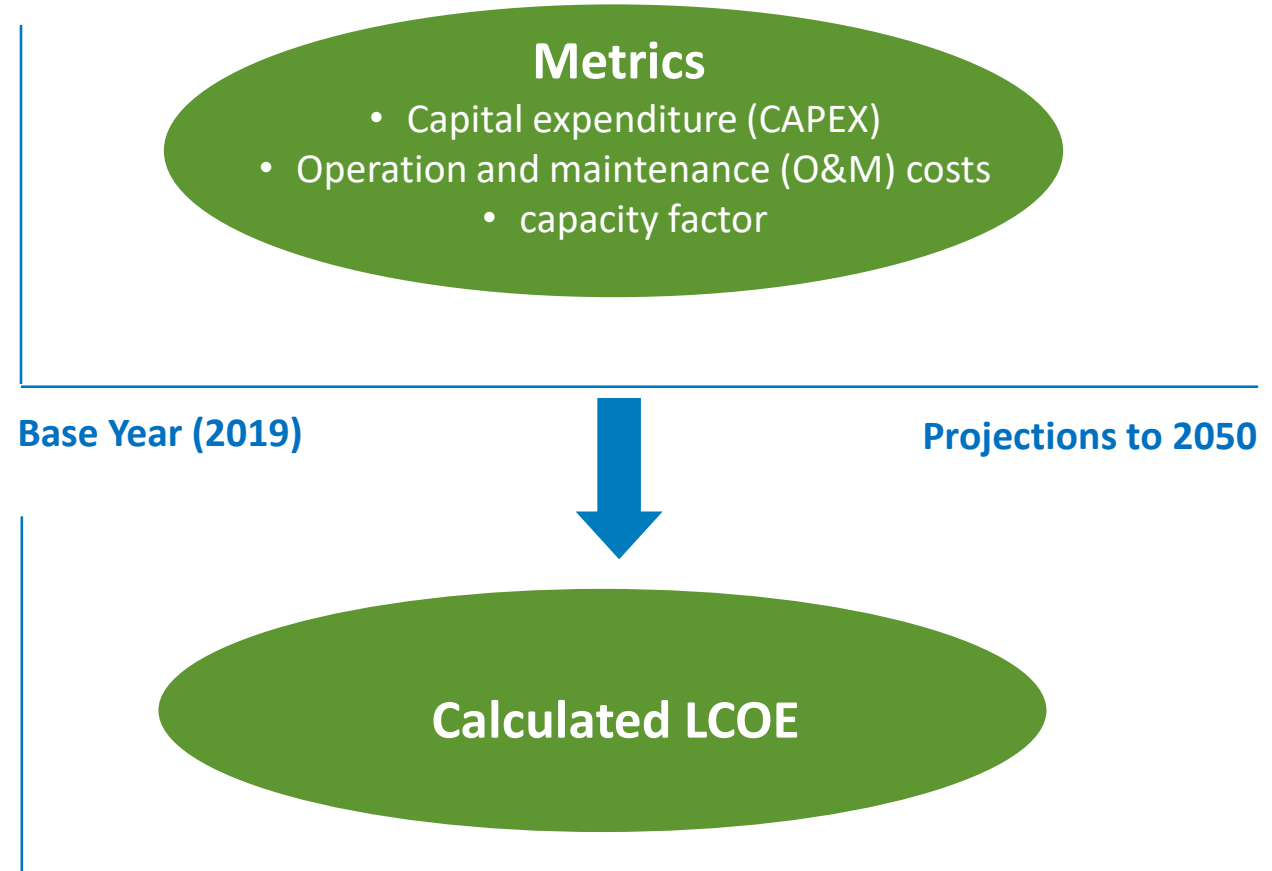

Base Year (2019)
Projections to 2050
Cost and performance data are:

- Provided for each:

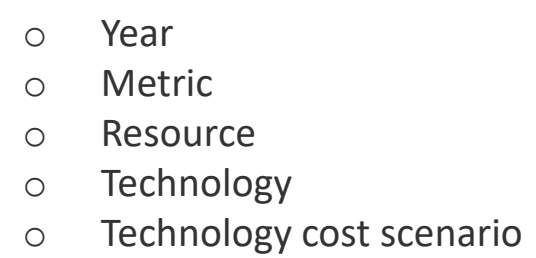

- Used to calculate LCOE for each financial assumptions scenario.

LCOE is provided as a summary metric but is not used as a ReEDS model input. Its limitations are described in the documentation. The user can select or specify financial assumptions for calculating LCOE. 


\section{Technologies}

\section{Covered}

\section{Renewable Energy}

Technologies (EERE/NREL)

Wind

- Land-based

- Offshore

Solar

- Utility PV

- Commercial and industrial PV

- Residential PV

- Utility PV-plus-battery

- Concentrating solar power (CSP)

Hydropower

- Non-powered dams (NPD)

- New stream-reach development (NSD)

- Pumped-storage hydropower

Geothermal (Flash and Binary)

- Hydrothermal

- Near-field enhanced geothermal systems (EGS)

- Deep EGS

Storage

- Utility-scale

- Commercial-scale

- Residential
Fossil with Carbon Capture and Storage Options (FE)

Natural Gas

- Natural gas combined cycle (NGCC)

- NGCC w/ 90\% carbon capture and storage (CCS)

- Combustion turbine (CT)

Coal

- Supercritical pulverized coal (SCPC)

- SCPC w/ 36\% CCS

- SCPC w/90\% CCS

- Integrated gasification combined-cycle (IGCC)

Conventional (EIA AEO 2021)

Nuclear

- Gen 3

Biopower

- Dedicated 


\section{Methodology Overview: Three Steps}

\section{Define resource bins for each technology}

Group range of resources for continental United States into bins with common resource quality and characteristics, or develop representative plants

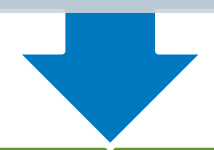

\section{Develop cost and performance data}

Develop base year and projected values for Constant, Mid, and Low technology cost scenarios for CAPEX, capacity factor, and operation and maintenance (O\&M)

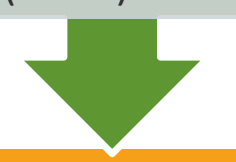

\section{Calculate LCOE (for selected technologies)}

Use selected financial assumptions to calculate LCOE from CAPEX, capacity factor, and O\&M 


\section{Step 1: Define Technologies/Resource Bin Categories}

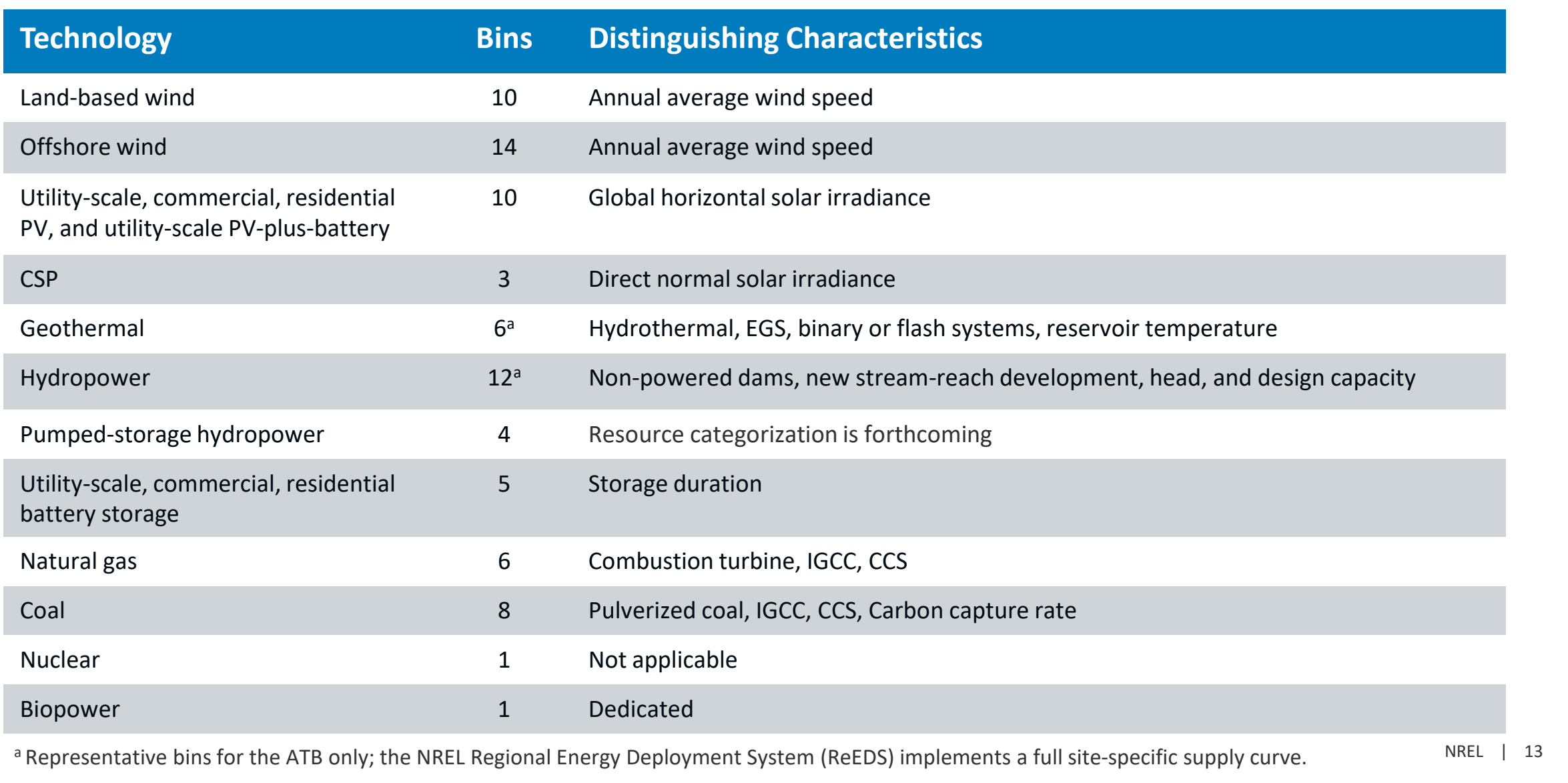




\section{Example of Technology/Resource Bins: Land-Based Wind}

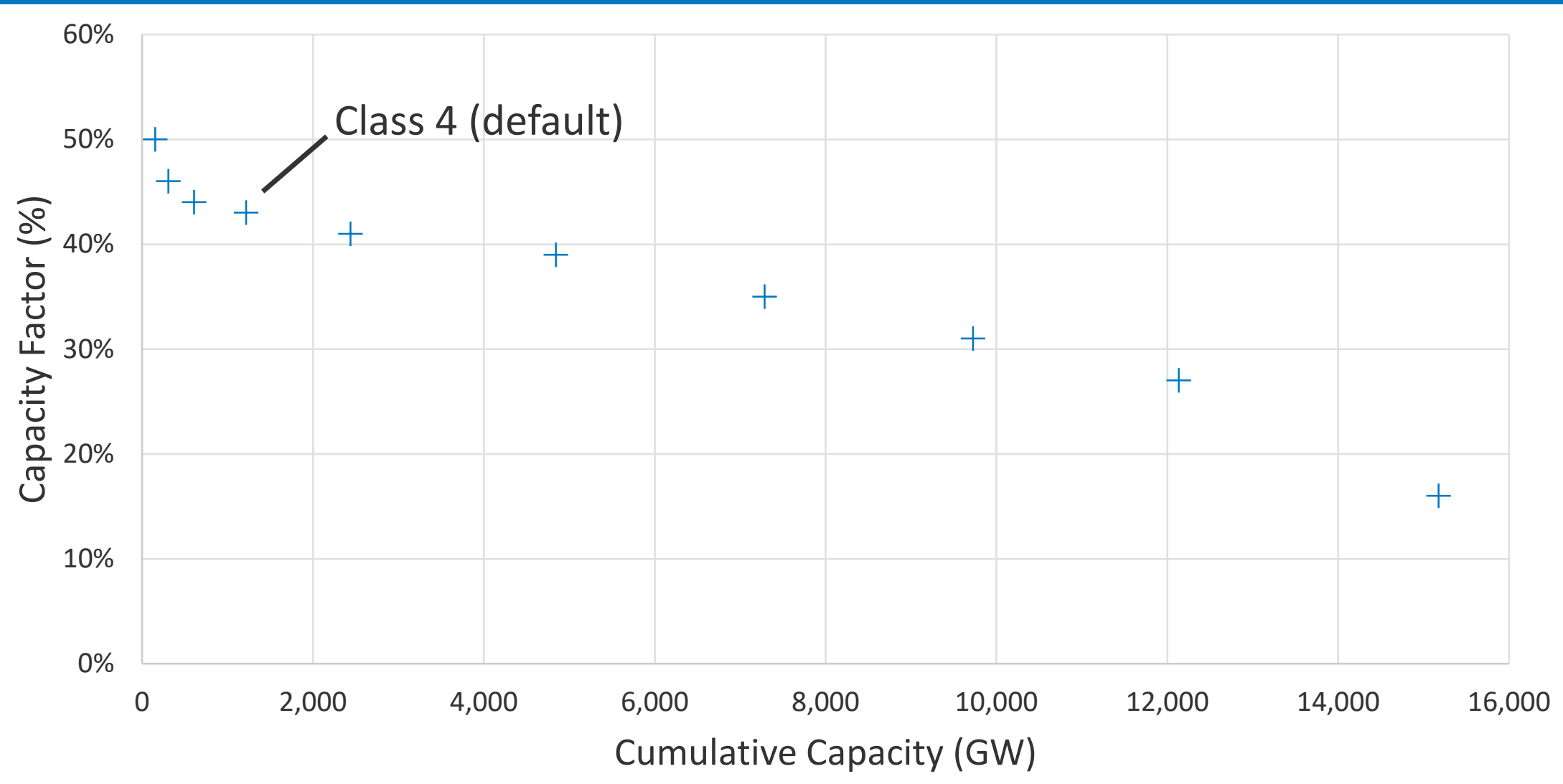




\section{Step 2: Develop Cost and Performance Data}

Base Year (2019): informed by market reports, market data, and bottom-up modeling

Projections: generally rely on bottom-up modeling and published studies; qualitatively harmonized to three projection scenarios:

Conservative

Technology Innovation

- Today's technology with little innovation

- Continued industrial learning

- Decreased public and private R\&D
Moderate Technology Innovation

- Widespread adoption of today's cutting edge

- Expected level of innovation

- Current levels of public and private $R \& D$
Advanced

Technology Innovation

- Market success of currently unproven innovation

- New technology architectures

- Increased public and private $R \& D$ 


\section{Sources of Base Year (2019)}

\section{Technology}

Land-based wind power plants

Offshore wind power plants

Utility, residential, and commercial PV plants

Concentrating solar power plants

Geothermal plants

Hydropower plants

\section{Source}

Capital expenditures (CAPEX) associated with wind plants installed in the interior of the country are used to characterize CAPEX for hypothetical wind plants with average annual wind speeds that correspond with the median conditions for recently installed wind facilities (Stehly et al. 2020). The operation and maintenance (O\&M) of $\$ 43 / \mathrm{kW}$-yr is estimated in the 2019 Cost of Wind Energy Review (Stehly et al. 2020); no variation of fixed operation and maintenance expenses (FOM) with wind speed class is assumed. Capacity factors align with performance in Wind Speed Classes 2-7, where most installations are located.

Base Year estimates are derived from a combination of bottom-up techno-economic cost modeling (Beiter et al. 2016) and experiential learning effects with economies of size and scale from higher turbine and plant ratings (Beiter et al. 2020). Bottom-up estimates from the 2020 ATB are brought forward one year (2018 to 2019) using the learning methodology.

CAPEX for 2019 are based on new bottom-up cost modeling and market data from Feldman et al. (2021). $\mathrm{O} \& \mathrm{M}$ costs are based on modeled pricing for a $100-\mathrm{MW}_{\mathrm{DC}}$, one-axis tracking system (Feldman et al. 2021). Resource classes were expanded from 5 to 10 and capacity factors are now based on weighted averages within specific global horizontal irradiance (GHI) bins.

Bottom-up cost modeling are from Turchi et al. (2019) for the updates to the System Advisor Model (SAM) cost components.

Bottom-up cost modeling use Geothermal Electricity Technology Evaluation Model (GETEM) and inputs from the GeoVision Business-as-Usual (BAU) scenario (DOE 2019).

Non-powered dam (NPD) data are based on bottom-up new 2020 cost analysis (Oladosu et al. 2021). New stream-reach development (NSD) data are retained from previous years and were based on the Hydropower Vision study (DOE 2016), with bottom-up cost modeling from the Hydropower Baseline Cost Modeling report (O'Connor et al. 2015). 


\section{Sources of Base Year (2019) continued}

\section{Technology}

Utility scale PV-plus-battery

Utility, residential, and commercial battery storage

Pumped-storage hydropower

Natural gas and coal

Nuclear and biopower plants

\section{Source}

CAPEX for 2019 are based on new bottom-up cost modeling and market data from Feldman et al. (2021). O\&M costs are based on modeled pricing for a $134-\mathrm{MW}_{\mathrm{DC}}$, one-axis tracking system coupled with 50-MW, 4hour battery storage (Feldman et al. 2021). The chosen configuration reflects recent and proposed utilityscale PV-plus-battery projects. Capacity factors and tax credits assume $75 \%$ of the energy used to charge the battery component is derived from the coupled PV (on an annual basis).

Current costs for utility-scale battery energy storage systems are based on a bottom-up cost model using the data and methodology for utility-scale battery energy storage systems in Feldman et al. (2021).

Resource characterizations with capital costs are forthcoming and will accompany the national closed-loop pumped-storage hydropower resource assessment. O\&M costs are from Mongird et al. (2020).

Estimates of performance and costs for currently available fossil-fueled electricity generating technologies are representative of current commercial offerings and/or projects that began commercial service within the past ten years (James et al. 2019).

These are Annual Energy Outlook (EIA 2021) reported costs. 


\section{Major Innovations Driving Projections (to 2050)}

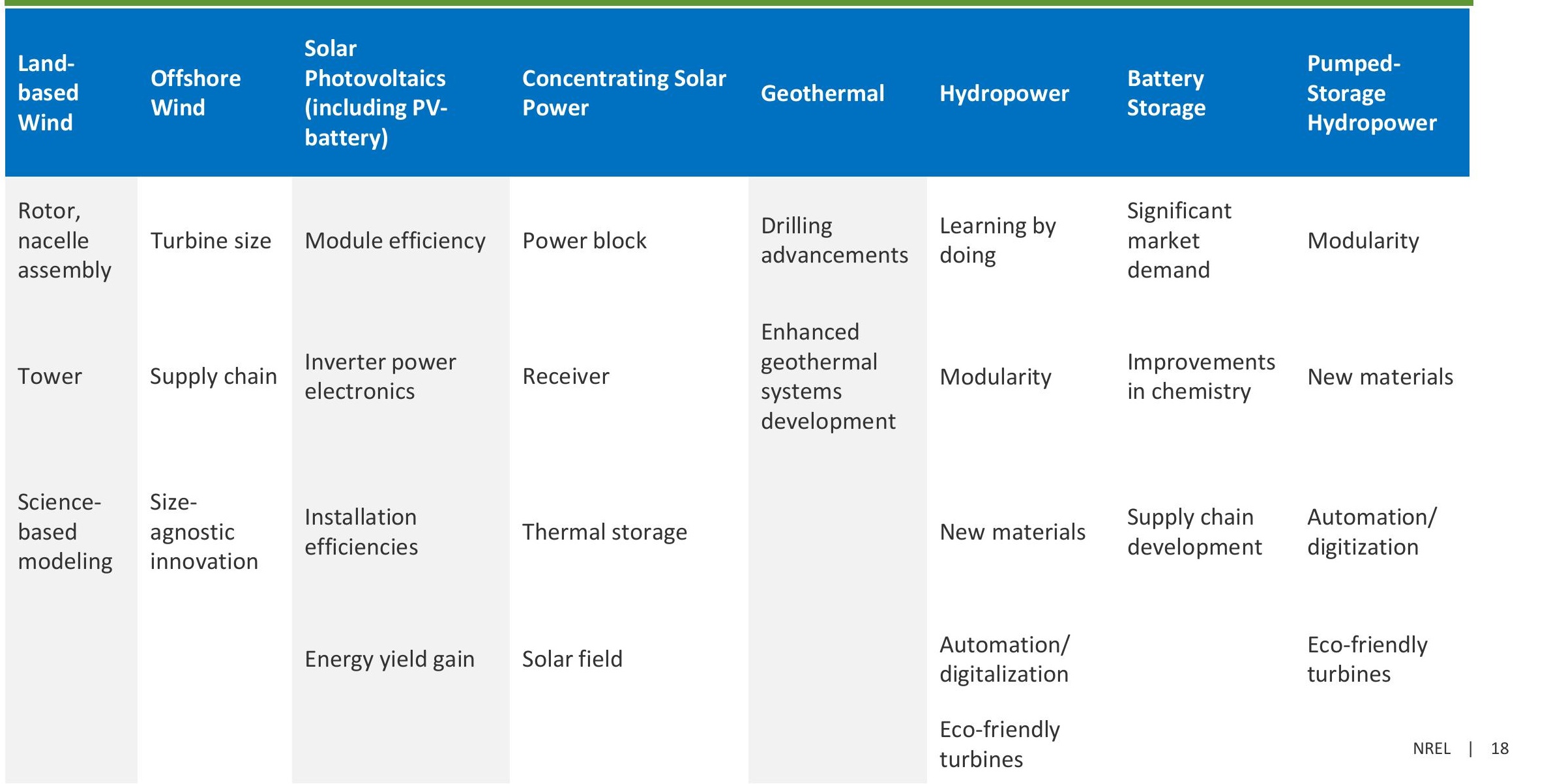




\section{Step 3: Calculate Levelized Cost of Energy (LCOE) (for selected technologies)}

Levelized Cost of Energy $=$

Fixed Charge Rate $\times$ Capital Expenditures + Fixed Operations and Maintenance Cost Capacity Factor $\times 8,760$ hours/year

+ Variable Operations and Maintenance Cost

+ Fuel Cost

LCOE is a summary metric that combines the primary technology cost and performance parameters: capital expenditures, operations expenditures, and capacity factor. See documentation at atb.nrel.gov.

Capacity factor refers to utilization for geothermal, hydropower, nuclear, and biopower.
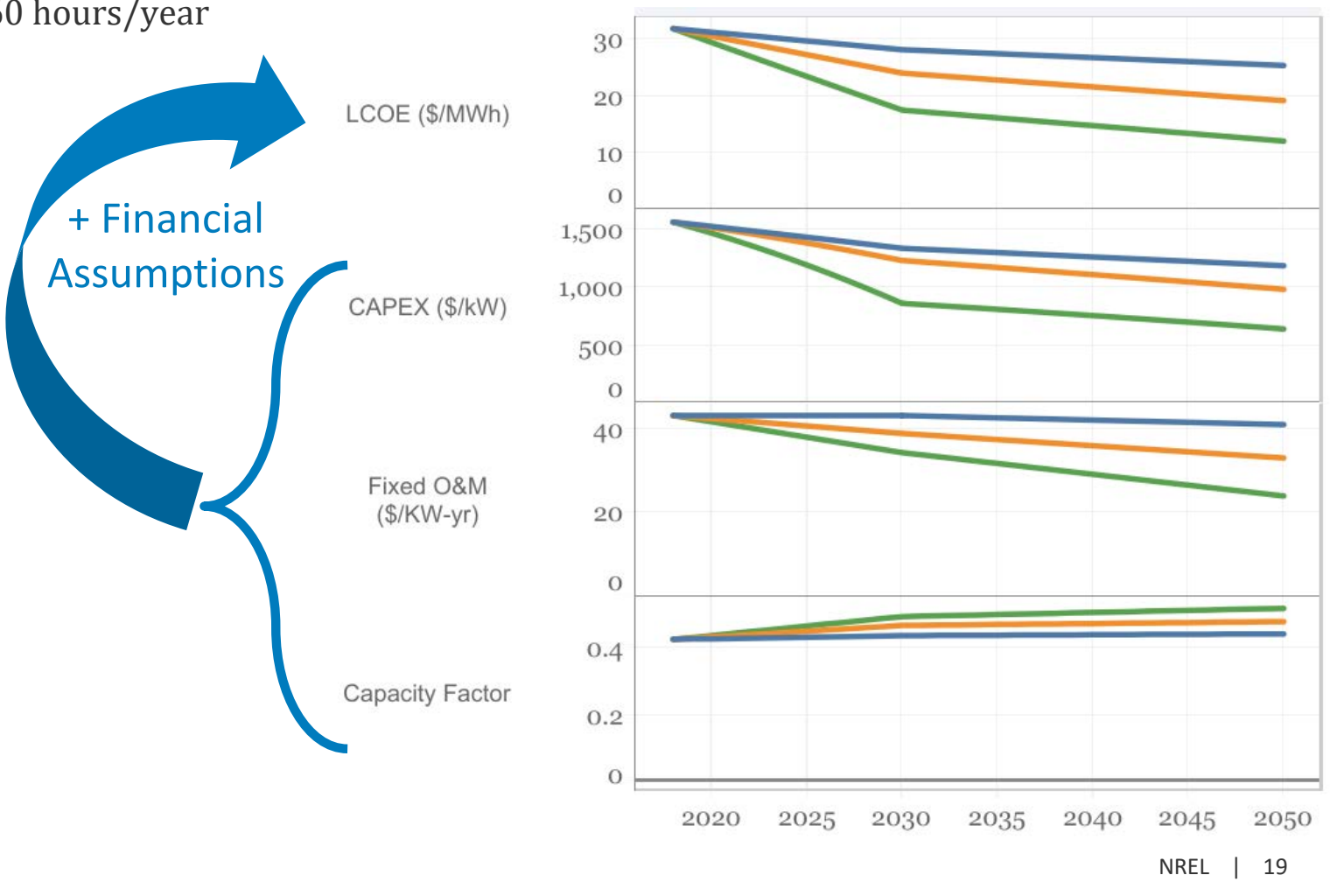


\section{All-Technology Changes in 2021 ATB}

- Modified values in the two financial cases (R\&D and Market + Policies) to reflect current assessments and policies

- Base year $=2019$

Dollar year $=2019$

Historical data includes data reported in 2019.

- General approach consistent with 2020 


\section{Web Demonstration}

- $\quad$ ATB Electricity Data Overview

- 2019 Base Year

- 2019-2050 trajectories

- Filter by technology, parameter, scenario, cost recovery period, year, (tech. detail)

- Downloads: slide deck, images, or Tableau workbook associated with each chart

- Example: Land-Based Wind

- Technology-specific interactive chart

- Scenario descriptions

- Representative technology

- Annual Technology Baseline Data Download

- About 


\section{Technology-Specific Highlights}

https://atb.nrel.gov/electricity/2021/changes in 2021 


\section{Technology-Specific Summary}

- $\quad$ Concentrating Solar Power: Component and system cost estimates for Base Year reference a 2017 industry survey and a 2018 cost analysis of recent market developments.

- Pumped-Storage Hydropower: This technology is new to the 2021 ATB.

- Hydropower: NPD data are based on new 2020 cost analysis.

- Photovoltaics: Projections are based on bottom-up techno-economic analysis of effects of improved module efficiency, inverters, installation efficiencies from assembly and design, all attributable to technological innovation. Resource categorization is split into 10 resource classes by irradiance instead of by representative location.

- $\quad$ Land-Based Wind: Projections are based on bottom-up technology analysis and cost modeling plus learning rates, with innovations that increase wind turbine size, improve controls, and enhance sciencebased modeling.

- $\quad$ Offshore Wind: Projections are based on experiential learning curves derived from market data and cost reductions associated with economies of size and scale.

- Geothermal: New data are now consistent with the GeoVision Study.

- Utility-Scale PV-plus-Battery: This technology is new to the 2021 ATB.

- Battery Storage: Updated projections are based on a new literature review. 


\section{Land-Based Wind}

Parameter

Multiple values

Scenario

All

Financials

Market + Policies

(c) $\mathrm{R} \& \mathrm{D}$

Cost Recovery Period

30 years

Technology Detail

Default

Default Technology Detail

Land-based Wind Speed Class 4

Conservative

Moderate

$\square$ Advanced

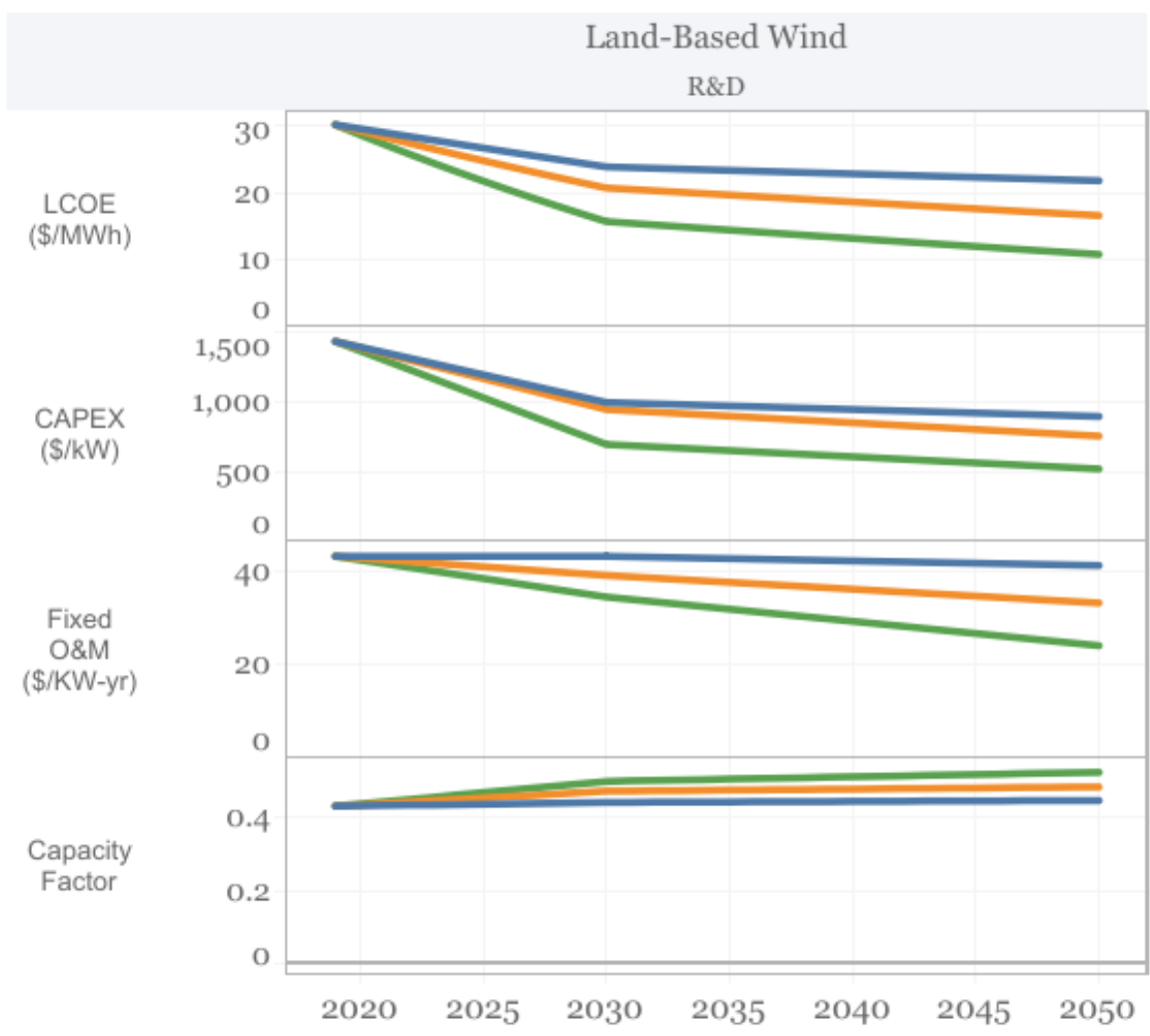

MNREL

https://atb.nrel.gov/
Parameter value projections by scenario, financial case, cost recovery period, and technological detail

Select the parameter (LCOE, CAPEX, Fixed O\&M, Capacity Factor, and FCR [fixed charge rate]), scenario, financial case, cost recovery period, and technological detail. The year represents the commercial online date. The default technology detail best aligns with recent or anticipated near-term installations. 


\section{Offshore Wind}

Parameter

Multiple values

Scenario

All

Financials

Market + Policies

() R\&D

Cost Recovery Period

30 years

Technology Detail

Default

Default Technology Detail

OffShore Wind Speed Class 3

Conservative

Moderate

Advanced

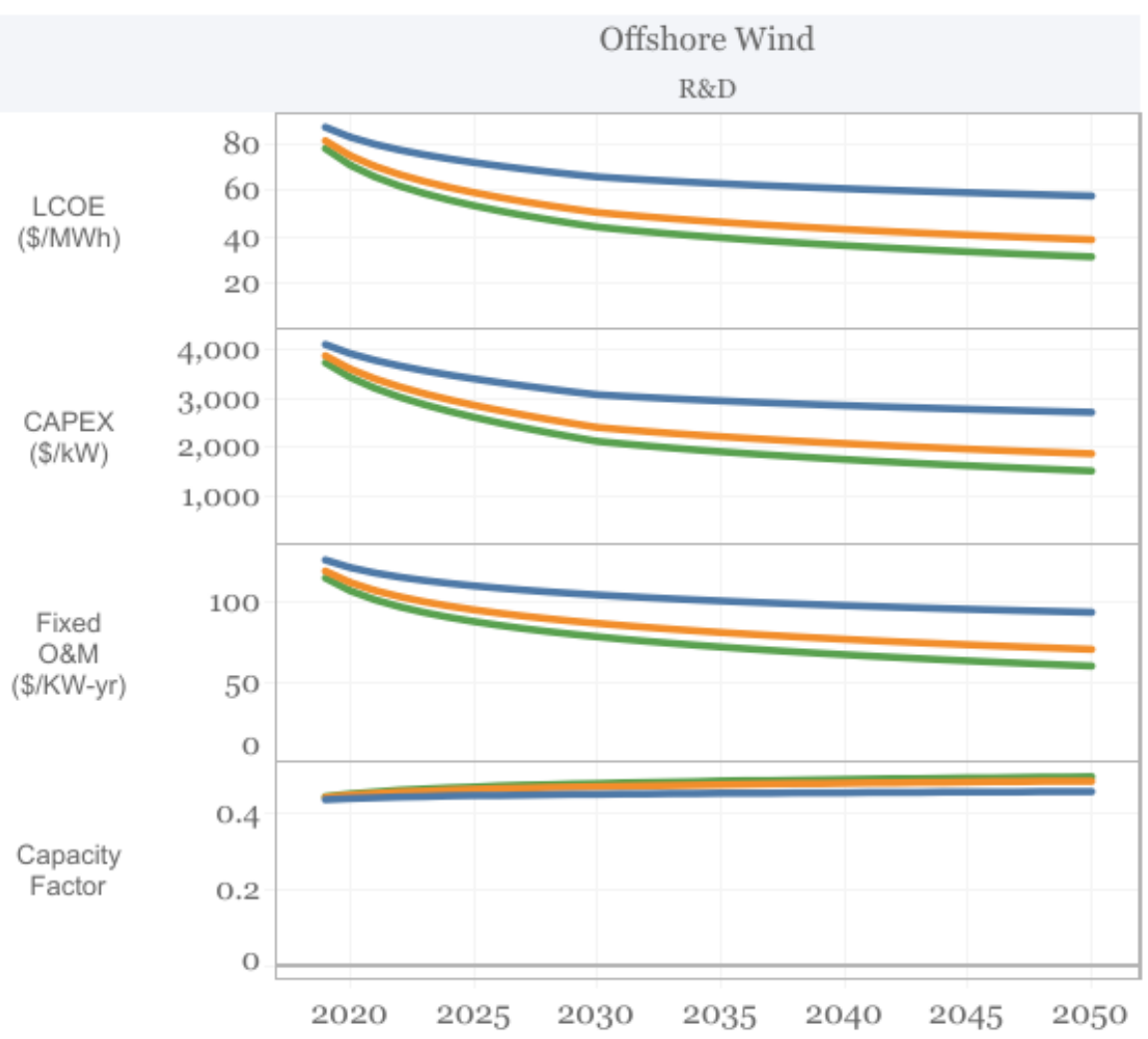

$\begin{array}{llllll}2020 & 2025 \quad 2030 & 2035 \quad 2040 \quad 2045 \quad 2050\end{array}$

MNREL

Parameter value projections by scenario, financial case, cost recovery period, and technological detail

Select the parameter (LCOE, CAPEX, Fixed O\&M, Capacity Factor, and FCR [fixed charge rate]), scenario, financial case, cost recovery period, and technological detail. The year represents the commercial online date. The default technology detail best aligns with recent or anticipated near-term installations. 


\section{Solar PV}

Parameter Scenario

Multiple values

All

Financials

Market + Policies

(b) $R \& D$

Cost Recovery Period

30 years

Technology Detail

Default

Default Technology Detail

Utility PV Class 5

Conservative

Moderate

Advanced

es

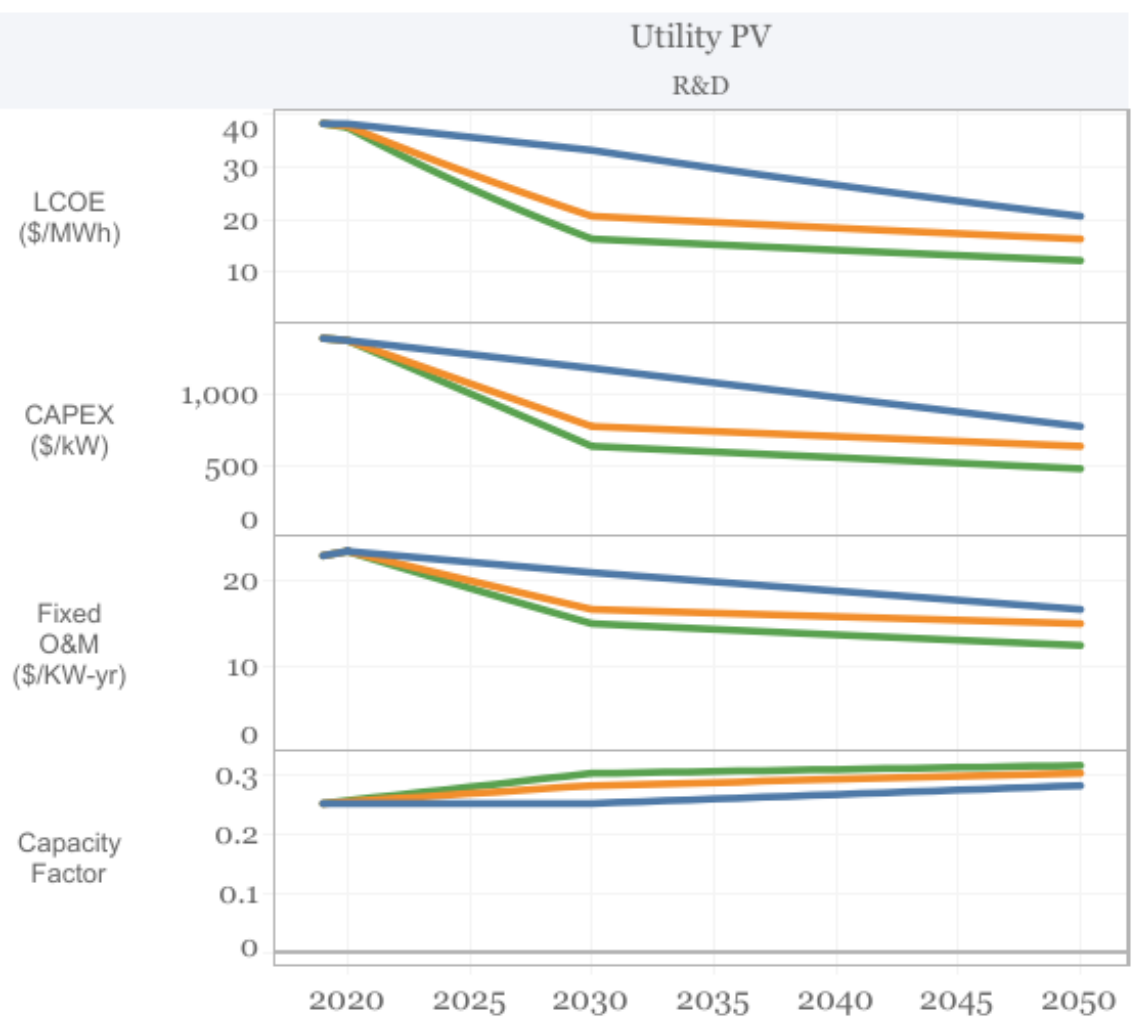

Utility PV

INREL

https://atb.nrel.gov/

Parameter value projections by scenario, financial case, cost recovery period, and technological detail

Select the parameter (LCOE, CAPEX, Fixed O\&M, Capacity Factor, and FCR [fixed charge rate]), scenario, financial case, cost recovery period, and technological detail. The year represents the commercial online date. The default technology detail best aligns with recent or anticipated near-term installations. 


\section{Concentrating Solar Power}

Parameter

Multiple values

Scenario

All

Financials

Market + Policies

C R\&D

Cost Recovery Period

30 years

Technology Detail

Default

Fixed

O\&M

(\$/KW-yr)

Default Technology Detail

CSP Class 2

$\square$ Conservative

Moderate

Advanced

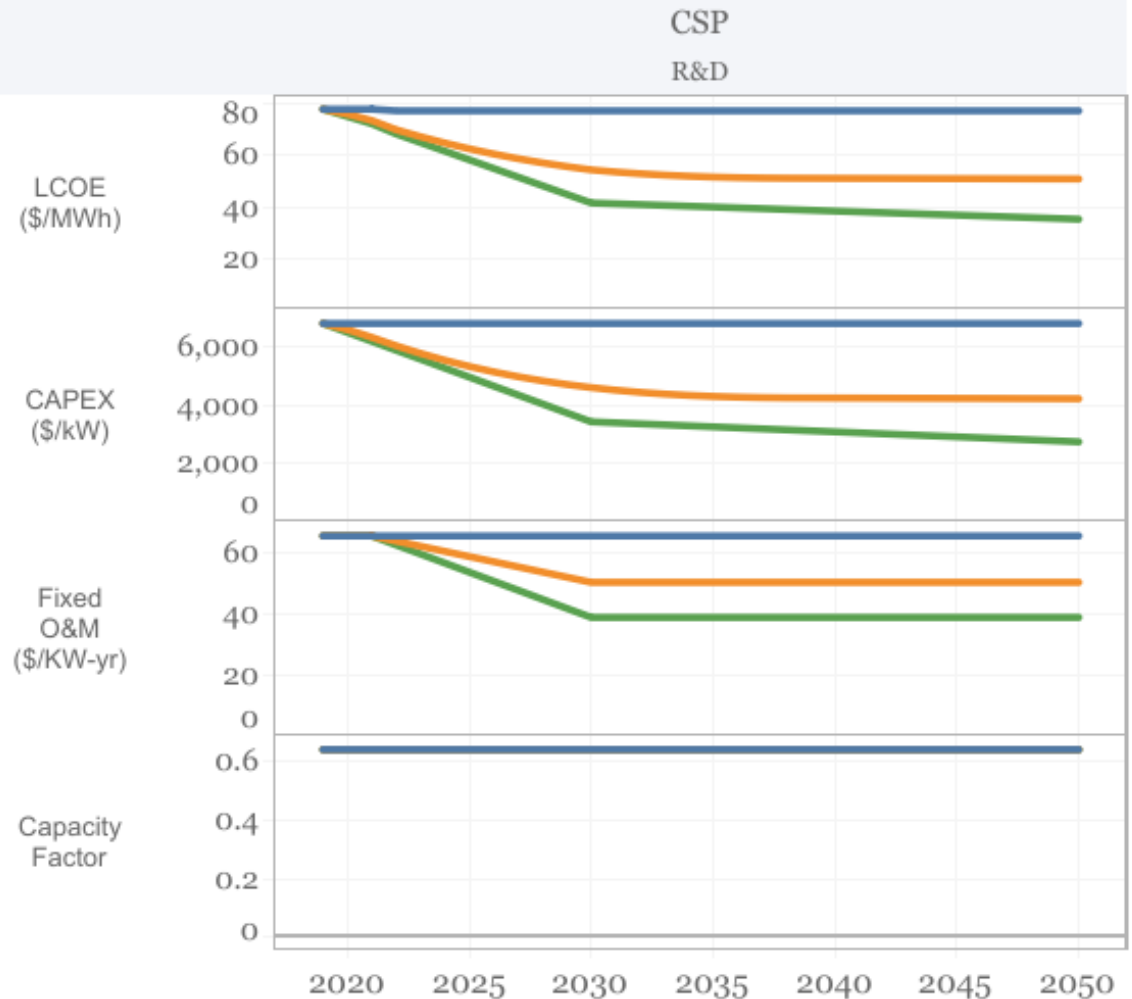

2020

Parameter value projections by scenario, financial case, cost recovery period, and technological detail

GNREL

https://atb.nrel.gov/
Select the parameter (LCOE, CAPEX, Fixed O\&M, Capacity Factor, and FCR [fixed charge rate]), scenario, financial case, cost recovery period, and technological detail. The year represents the commercial online date. The default technology detail best aligns with recent or anticipated near-term installations. 


\section{Geothermal}

\section{Parameter \\ Multiple values \\ Scenario \\ All}

Financials

Market + Policies

() R\&D

\section{Cost Recovery Period}

3o years

Technology Detail

Default

Default Technology Detail

Geothermal Hydrothermal Flash

Conservative

Moderate

advanced

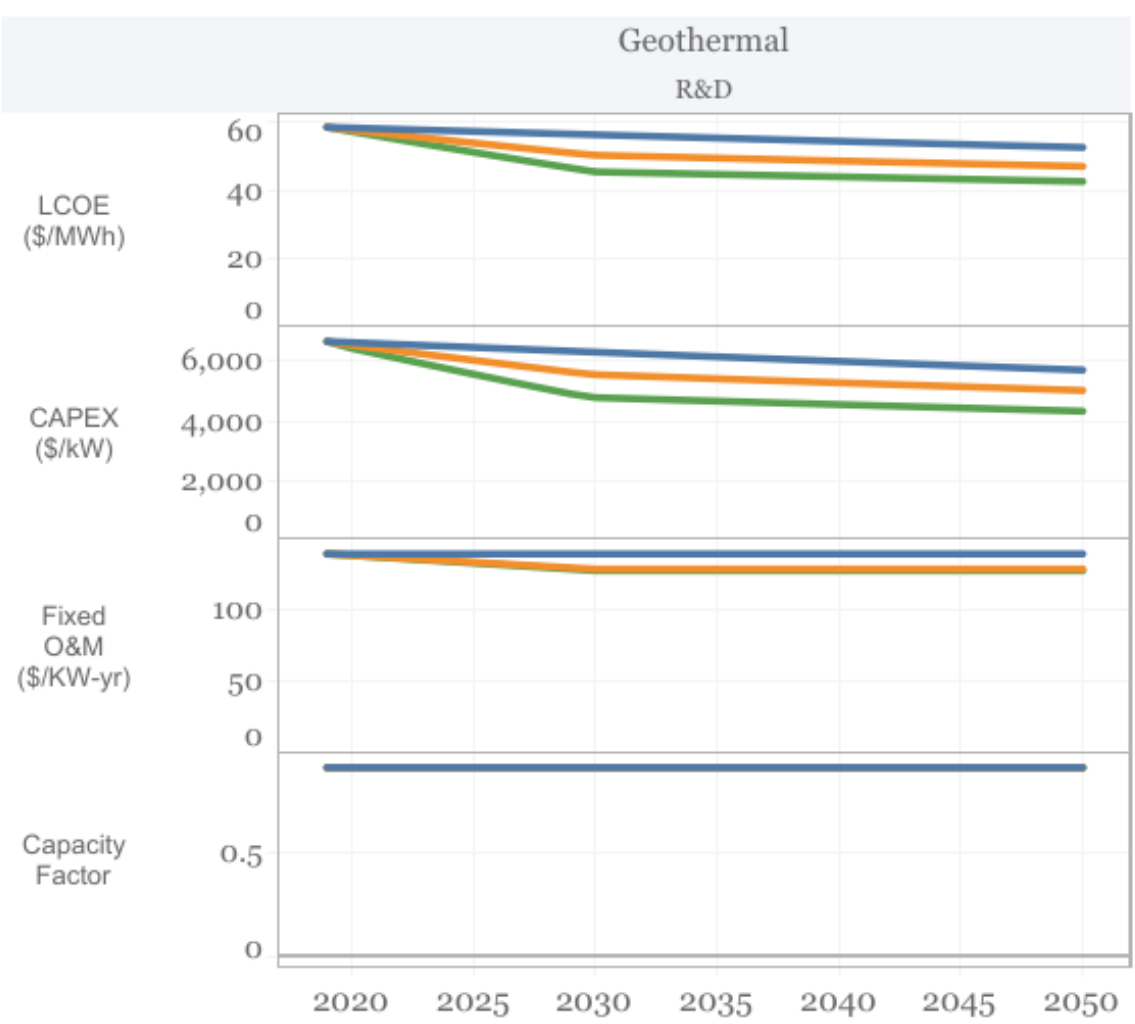

\section{MNREL}

https://atb.nrel.gov/

Parameter value projections by scenario, financial case, cost recovery period, and technological detail

Select the parameter (LCOE, CAPEX, Fixed O\&M, Capacity Factor, and FCR [fixed charge rate]), scenario, financial case, cost recovery period, and technological detail. The year represents the commercial online date. The default technology detail best aligns with recent or anticipated near-term installations. 


\section{Hydropower}

Parameter

Multiple values

Scenario

All

Financials

Market + Policies

(e) $R \& D$

Cost Recovery Period

30 years

Technology Detail

Default

$\underline{\text { Default Technology Detail }}$

Hydropower NPD 1

Conservative

Moderate

Advanced

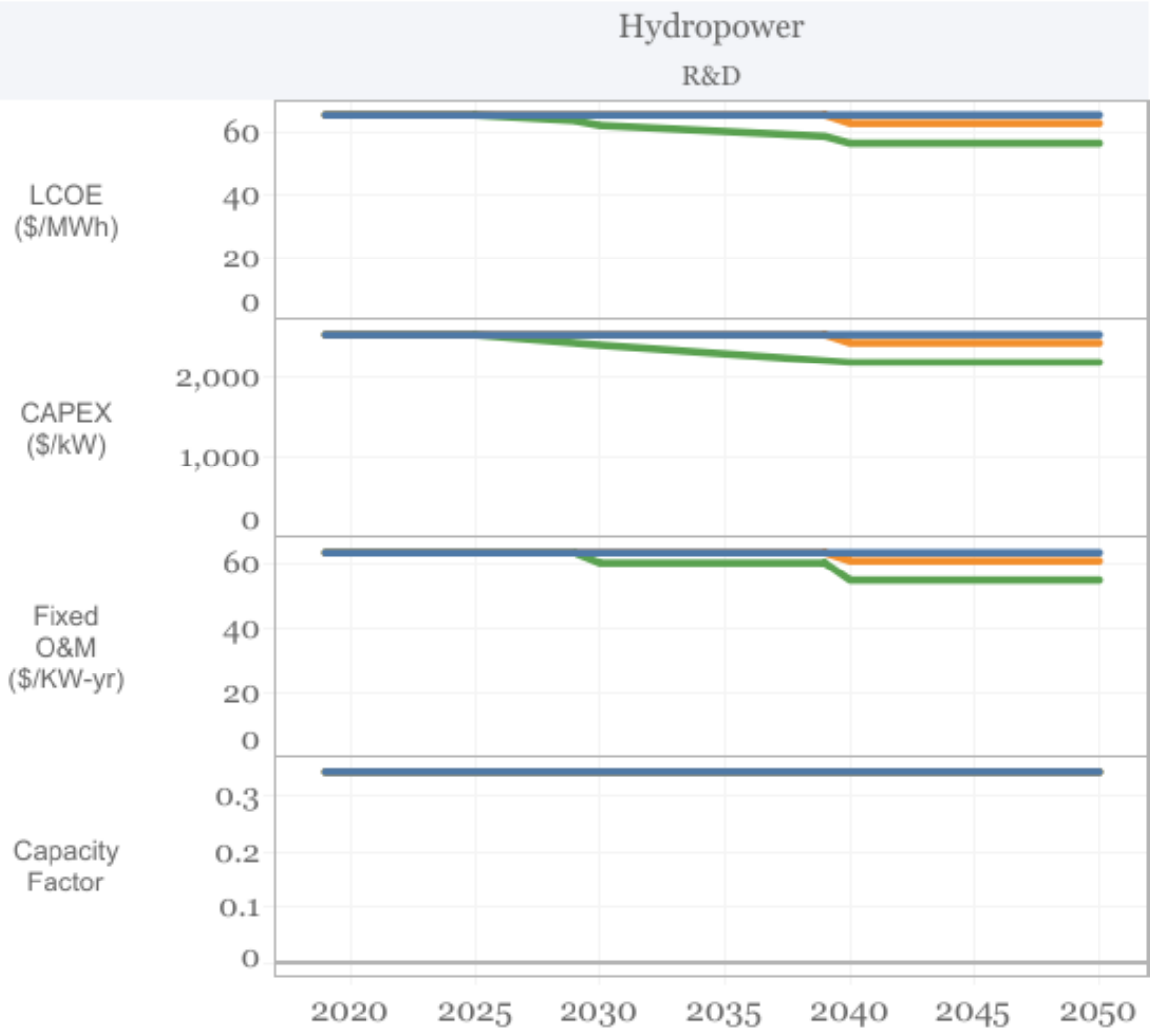

Hydropower

R\&D

LCOE

(

GNREL

https://atb.nrel.gov/
Parameter value projections by scenario, financial case, cost recovery period, and technological detail

Select the parameter ( $L C O E, C A P E X$, Fixed O\&M, Capacity Factor, and FCR [fixed charge rate]), scenario, financial case, cost recovery period, and technological detail. The year represents the commercial online date. The default technology detail best aligns with recent or anticipated near-term installations. 


\section{Battery Storage}

Parameter

Multiple values

Scenario

All

Financials

Market + Policies

(e) R\&D

Cost Recovery Period

30 years

Technology Detail

Default

Default Technology Detail

Utility-Scale Battery Storage $4 \mathrm{Hr}$

\section{RNREL}

ATB data for technologies on the website: https://atb.nrel.gov/

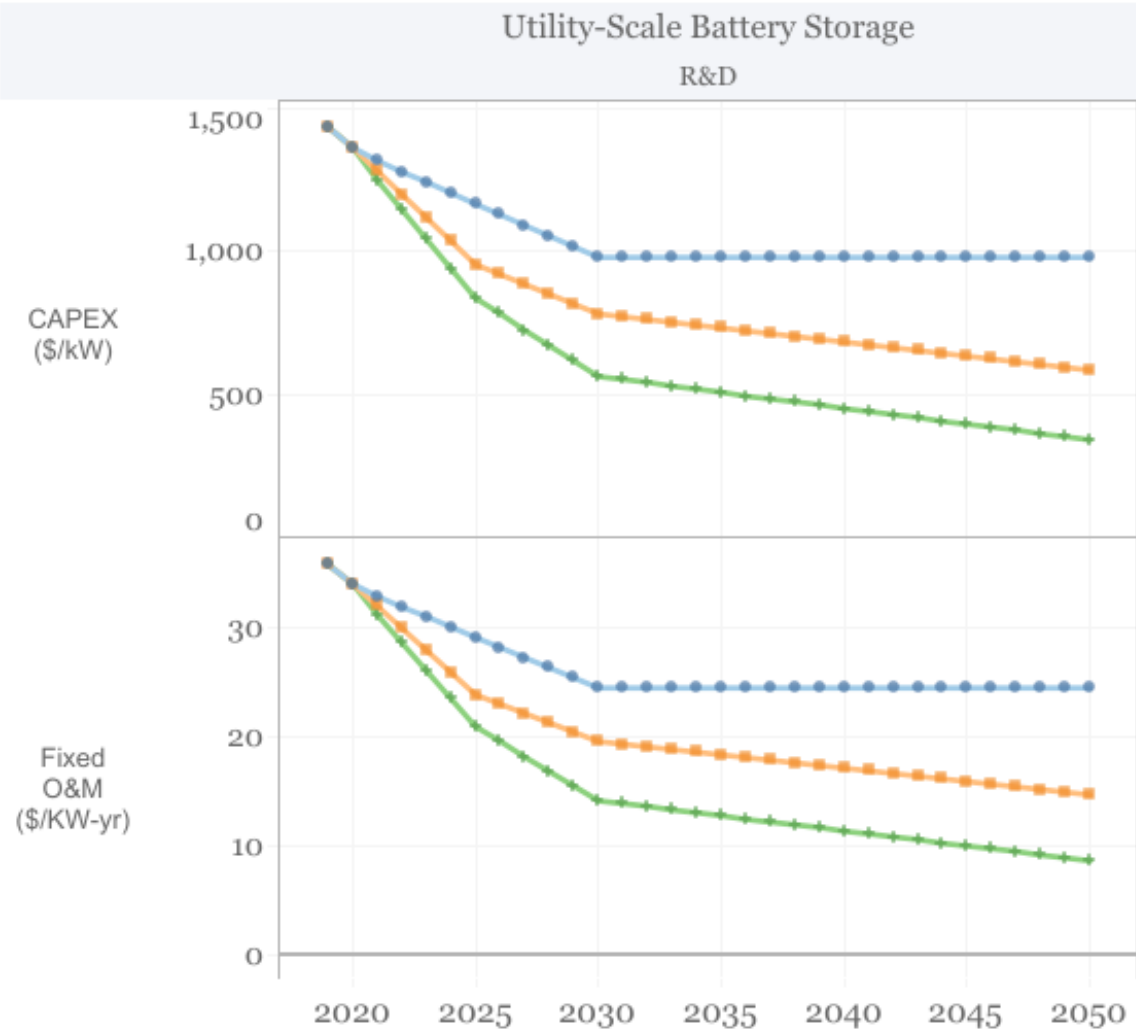

Parameter value projections by scenario, financial case, cost recovery period, and technological detail

Select the parameter (LCOE, CAPEX, Fixed O\&M, Capacity Factor, and FCR [fixed charge rate]), scenario, financial case, cost recovery period, and technological detail. The year represents the commercial online date.

The default technology detail best aligns with recent or anticipated near-term installations. 


\section{Utility-Scale PV-plus-battery}

Parameter

Multiple values

Scenario

All

Financials

Market + Policies

(c) R\&D

Cost Recovery Period

30 years

Technology Detail

Default

Default Technology Detail

Utility-Scale PV+Battery Class 5

\section{RNREL}

ATB data for technologies on the website: https://atb.nrel.gov/
Utility-Scale PV-Plus-Battery

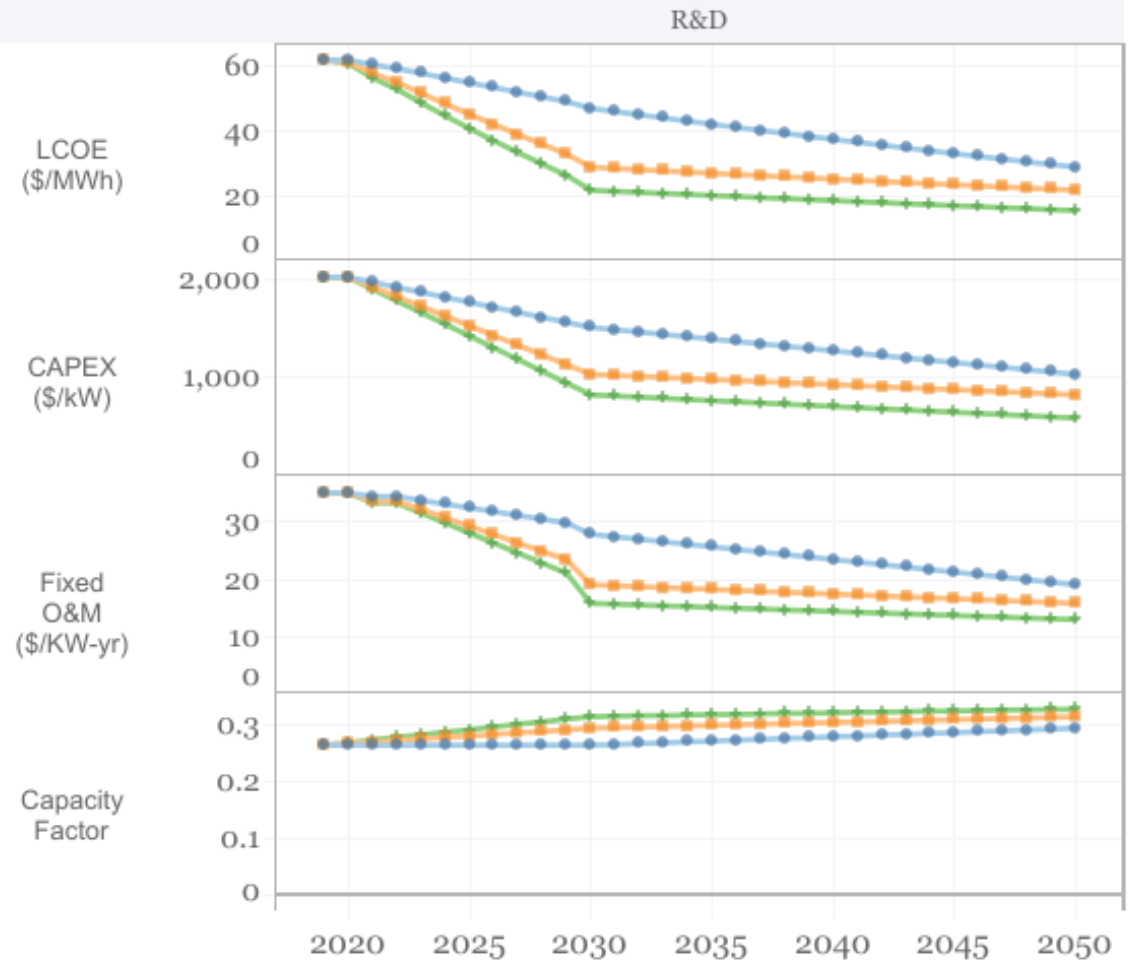

Parameter value projections by scenario, financial case, cost recovery period, and technological detail

Select the parameter (LCOE, CAPEX, Fixed O\&M, Capacity Factor, and FCR [fixed charge rate]), scenario, financial case, cost recovery period, and technological detail. The year represents the commercial online date. The default technology detail best aligns with recent or anticipated near-term installations. 


\section{Pumped-Storage Hydropower}

Parameter

Multiple values

Scenario

All

To be added

during 2021:

Capital costs and resource potential

Market + Policies

\section{Financials}

(C) R\&D

Cost Recovery Period

30 years

Technology Detail

Default

\section{Default Technology Detail}

Pumped Storage Hydropower Class 3

Conservative

Moderate

advanced

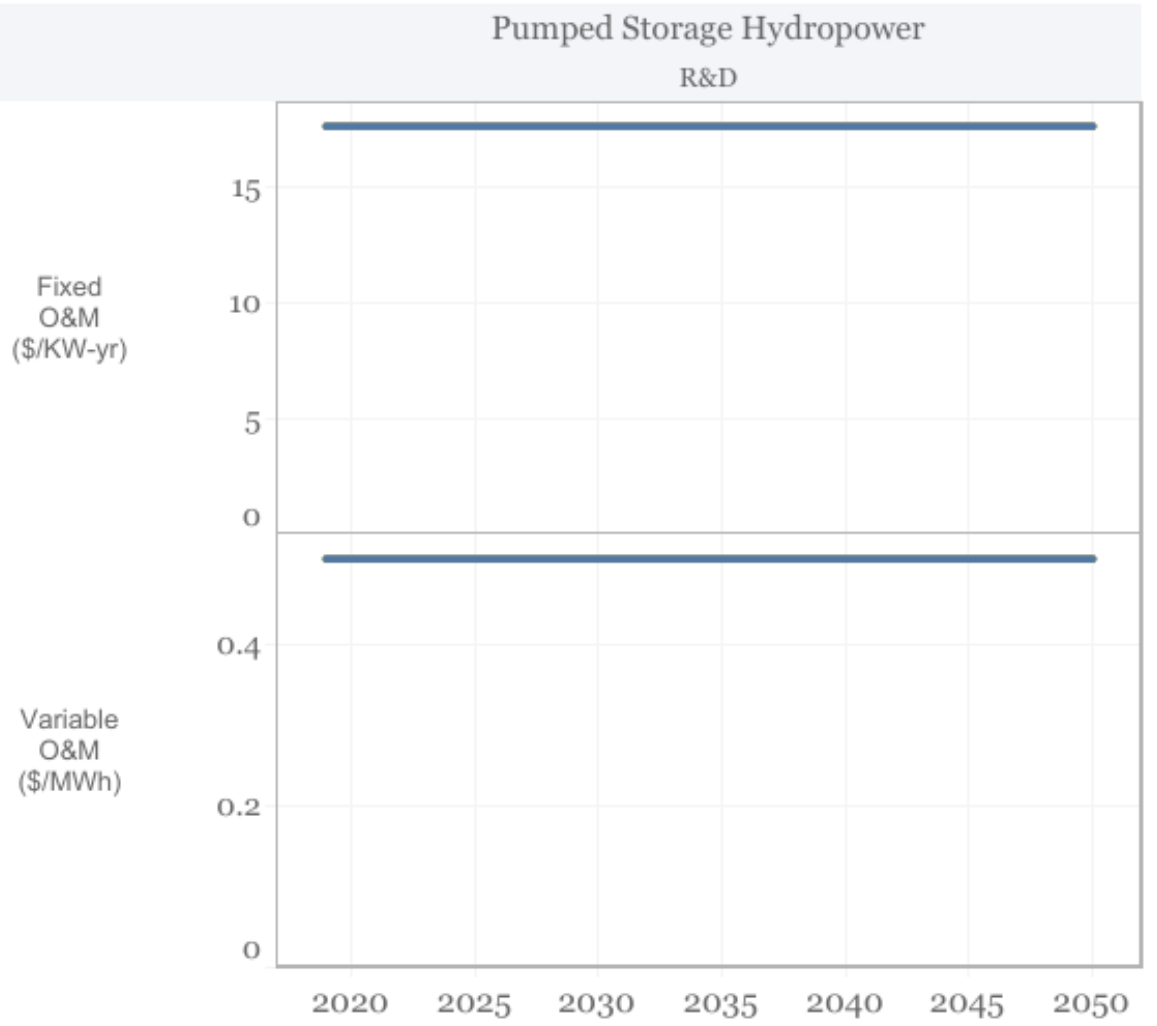

GNREL
Parameter value projections by scenario, financial case, cost recovery period, and technological detail

Select the parameter (LCOE, CAPEX, Fixed O\&M, Capacity Factor, and FCR [fixed charge rate]), scenario, financial case, cost recovery period, and technological detail. The year represents the commercial online date. The default technology detail best aligns with recent or anticipated near-term installations. 


\section{Fossil Energy Capital Cost Projections}

$\begin{array}{ll}\begin{array}{l}\text { Technology } \\ \text { All }\end{array} & \begin{array}{l}\text { Parameter } \\ \text { CAPEX }\end{array} \\ \text { Scenario } & \\ \text { All } & \\ & \\ \text { Financials } & \text { CRP Years } \\ \text { Carket + Policies } & \bigcirc_{30}^{20} \\ & \bigcirc_{55}^{\text {R\&D }} \\ & \bigcirc_{75}\end{array}$

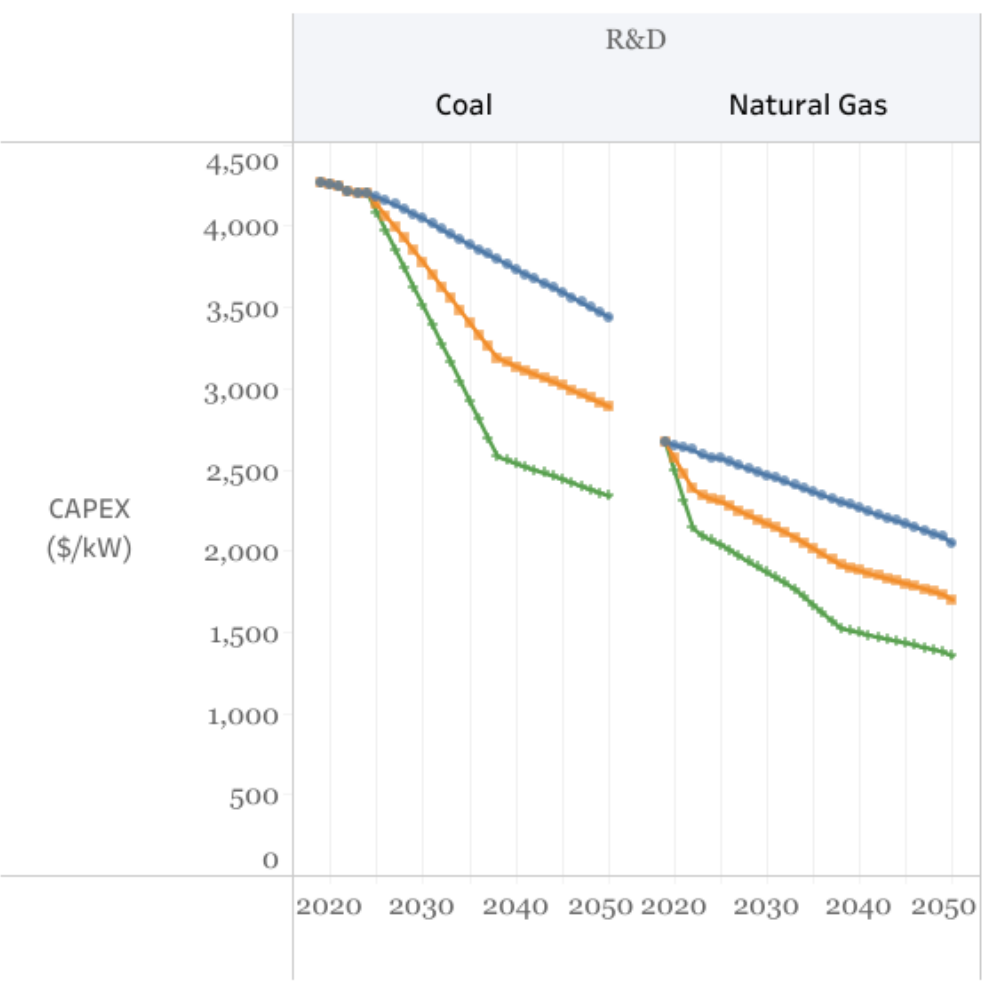

Technology Sub-Group Multiple values

RNREL

ATB data for technologies on the website: https://atb.nrel.gov/
Parameter value projections by scenario, financial case, cost recovery period, and technological detail Select the parameter (LCOE, CAPEX, Fixed O\&M, Capacity Factor, and FCR [fixed charge rate]), scenario, financial case, cost recovery period, and technological detail. The year represents the commercial online date. The default technology detail best aligns with recent or anticipated near-term installations. Scenarios are labeled with ATB names 


\section{Biopower and Nuclear}

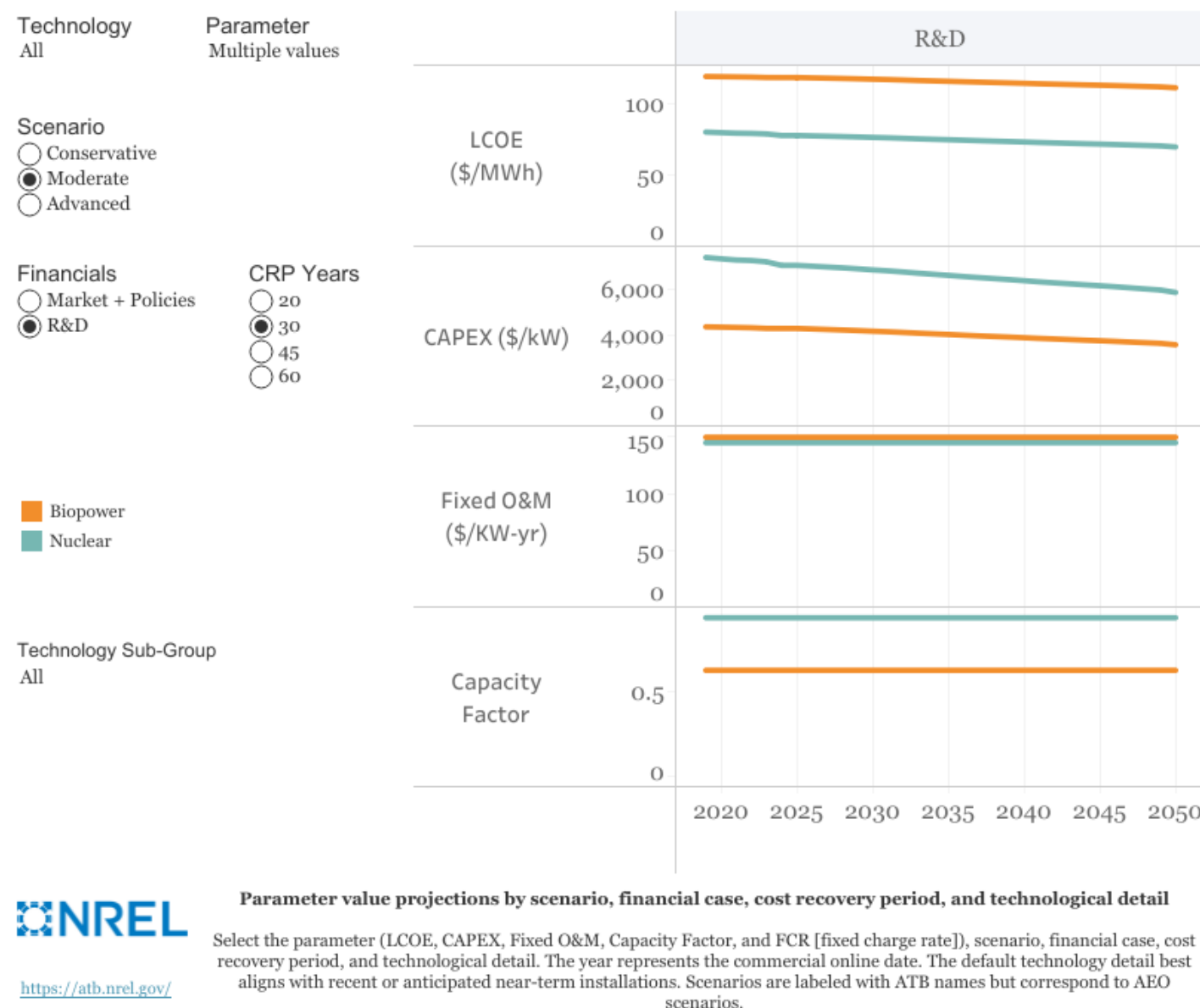




\section{Financial Cases and Methods}

https://atb.nrel.gov/electricity/2021/financial cases \& methods 


\section{ITC/PTC by Year}

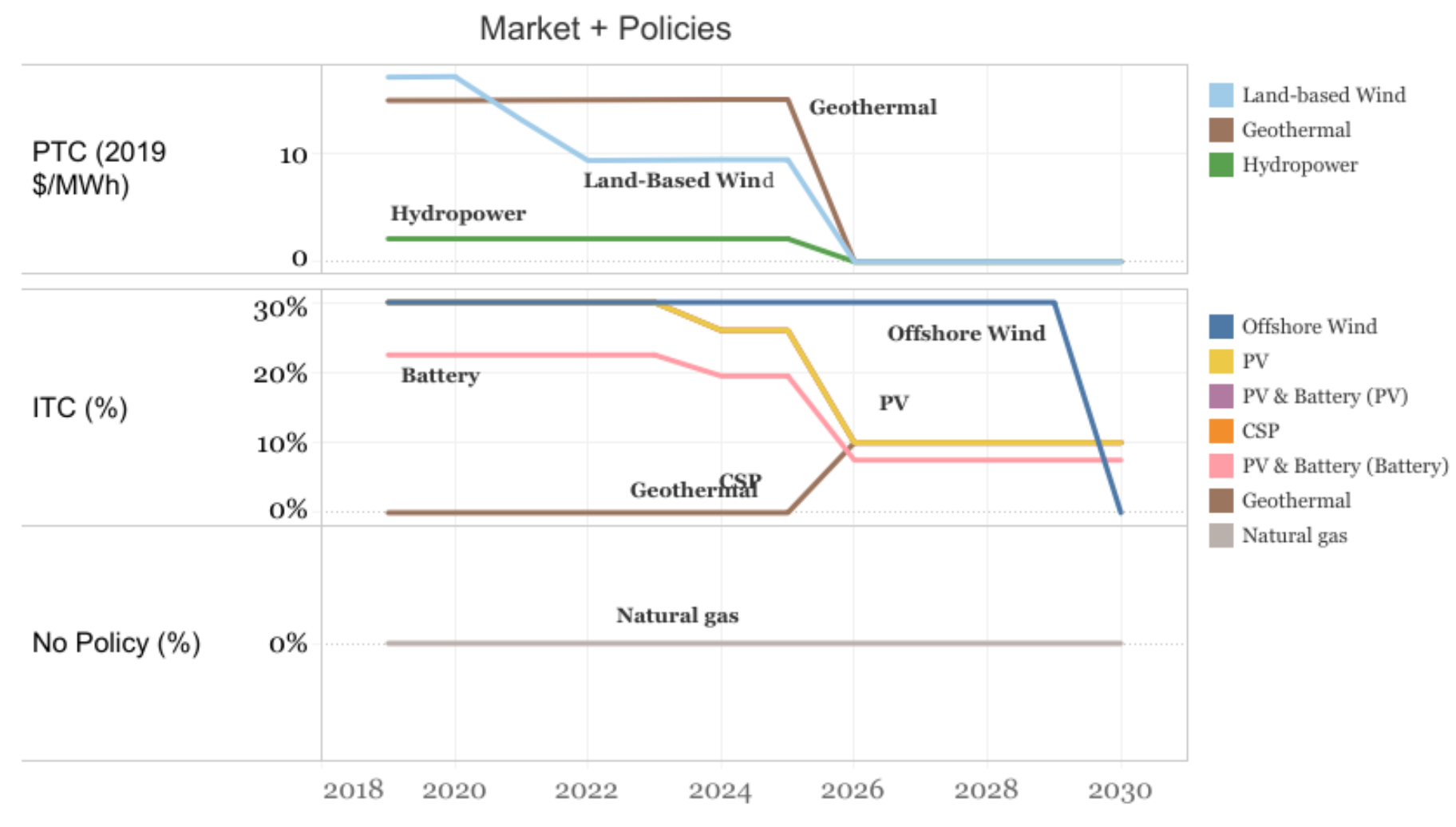

MNREL https://atb2021.nrel.gov/ 


\section{Term Debt Fraction by Financial Case}

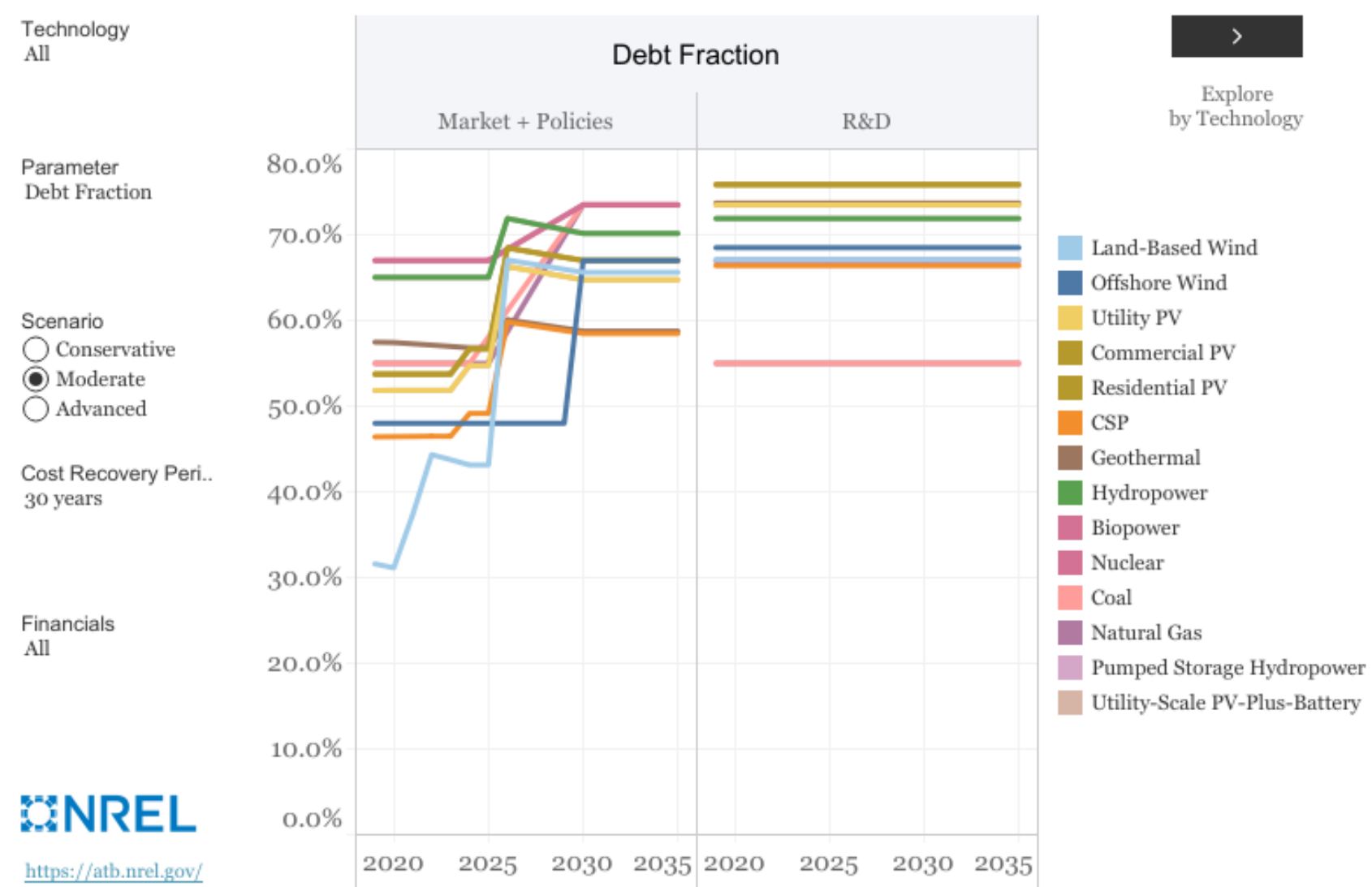




\section{Term WACC (Real) by Financial Case}

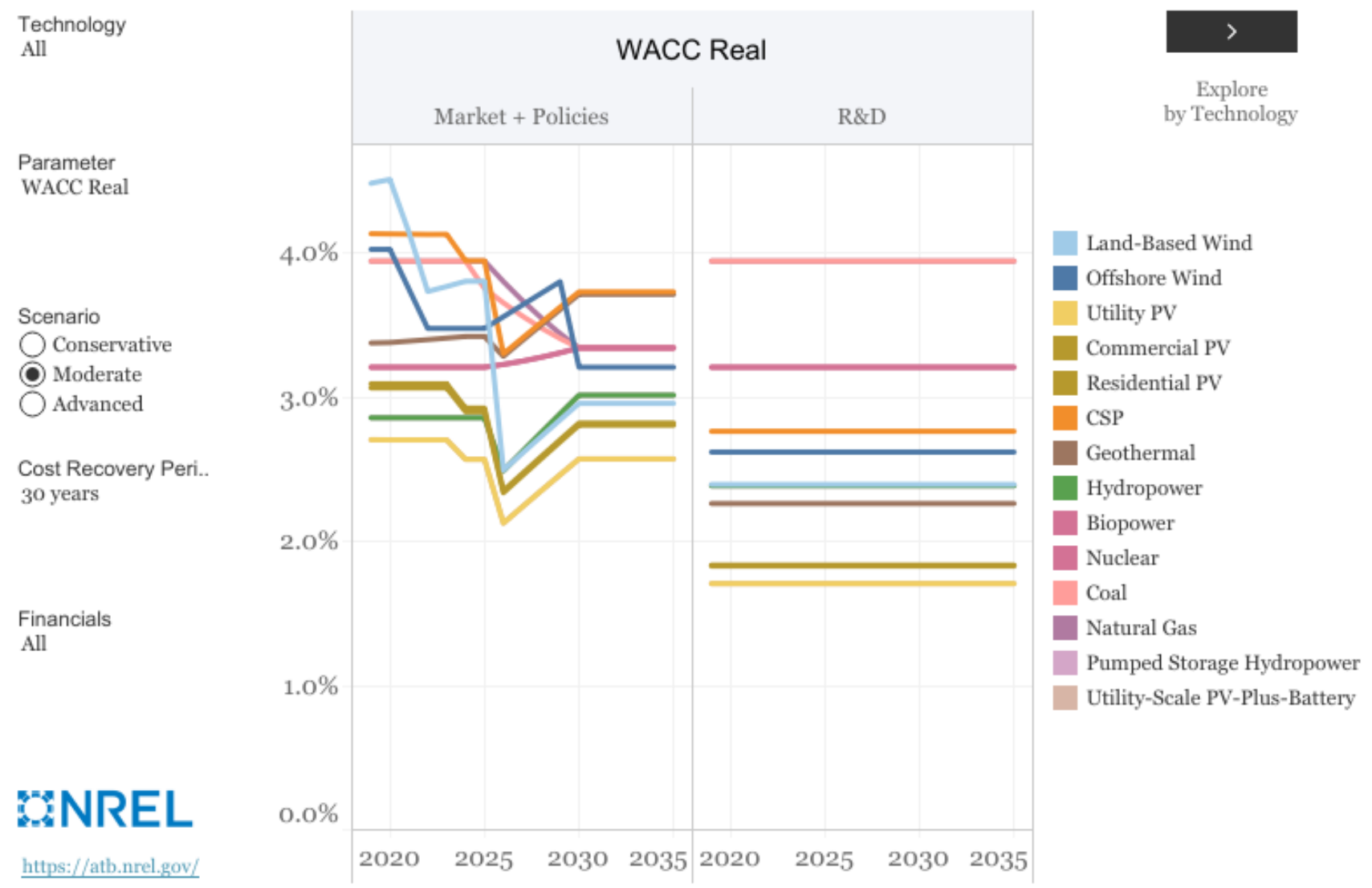




\section{LCOE by Financial Case}

Technology

Multiple value

Parameter

LCOE

Scenario

$\square$ Conservative

Financials

$\square$ Moderate

Advanced

- Land-based Winc

- OffShore Wind

* $\quad \operatorname{csp}$

$\star$ Geothermal

- Hydropower

$\triangleleft$ utility-Scale PV-Plus-Battery

Cost Recovery Period

30 years

\section{MNREL}

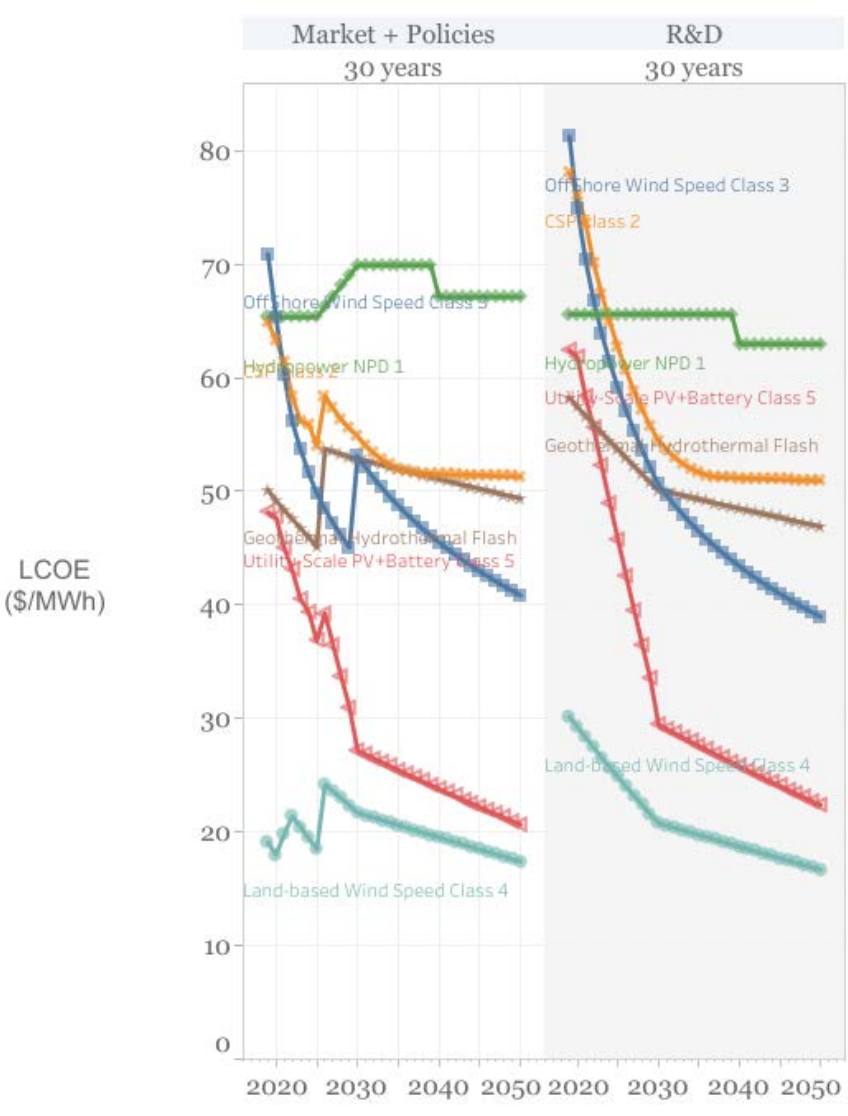

20202030204020502020203020402050 
Conclusion 


\section{The Vision}

The ATB, a flagship analytic product, facilitates access to credible, consistent, transparent, timely, relevant, and public data about current and future energy technologies and systems for a large and diverse audience.
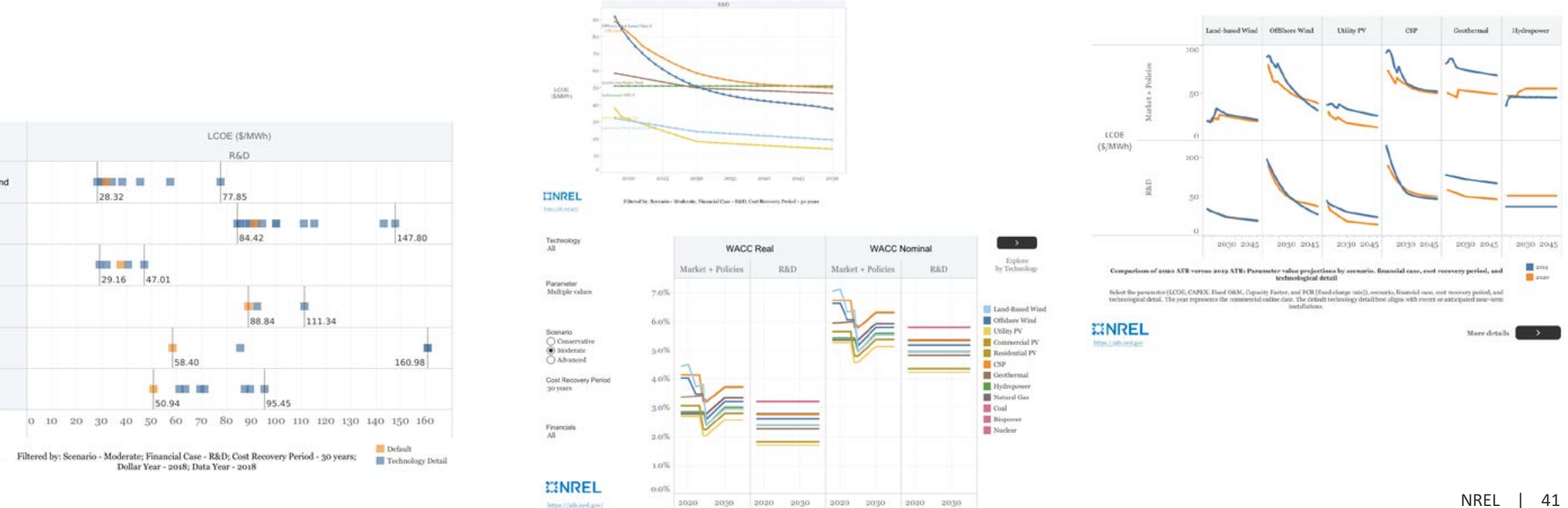
Sign up for updates!
Register as an ATB user to receive ATB news and updates.

https://atb.nrel.gov/contact/register/ 


\title{
Thank you!
}

\section{atb.nrel.gov}

\author{
NREL/PR-6A20-80095
}

This work was authored in part by the National Renewable Energy Laboratory, operated by Alliance for Sustainable Energy, LLC, for the U.S. Department of Energy (DOE) under Contract No. DE-AC36-08G028308. Funding provided by U.S. Department of Energy Office of Energy Efficiency and Renewable Energy Strategic Priorities and Impacts Analysis and Office of Renewable Power. The views expressed in the article do not necessarily represent the views of the DOE or the U.S. Government. The U.S. Government retains and the publisher, by accepting the article for publication, acknowledges that the U.S. Government retains a nonexclusive, paid-up, irrevocable, worldwide license to publish or reproduce the published form of this work, or allow others to do so, for U.S. Government purposes. 


\section{References}

For a full list of ATB references, see https://atb.nrel.gov/electricity/2021/references.php.

Beiter, Philipp, Walter Musial, Aaron Smith, Levi Kilcher, Rick Damiani, Michael Maness, Senu Sirnivas, et al. 2016. A Spatial-Economic CostReduction Pathway Analysis for U.S. Offshore Wind Energy Development from 2015-2030. Golden, CO: National Renewable Energy Laboratory. NREL/TP-6A20-66579. https://doi.org/10.2172/1324526.

Beiter, Philipp, Walt Musial, Patrick Duffy, Aubryn Cooperman, Matt Shields, Donna Heimiller, and Mike Optis. 2020. The Cost of Floating Offshore Wind Energy in California between 2019 and 2032. Golden, CO: National Renewable Energy Laboratory. NREL/TP-5000-77384. https://doi.org/10.2172/1710181.

DOE (U.S. Department of Energy). 2019. GeoVision: Harnessing the Heat Beneath Our Feet. Washington, D.C.: U.S. Department of Energy. DOE/EE-1306. https://www.energy.gov/sites/prod/files/2019/06/f63/GeoVision-full-report-opt.pdf.

- - . 2016. Hydropower Vision: A New Chapter for America's Renewable Electricity Source. Washington, D.C.: U.S. Department of Energy. DOE/GO-102016-4869. https://www.energy.gov/sites/prod/files/2018/02/f49/Hydropower-Vision-021518.pdf.

- - - 2011. U.S. Billion-Ton Update: Biomass Supply for a Bioenergy and Bioproducts Industry. Oak Ridge, TN: Oak Ridge National Laboratory. DOE/EE-0363. https://doi.org/10.2172/1023318.

EIA (U.S. Energy Information Administration). 2021. “Annual Energy Outlook 2021.” Energy Information Administration, January 2021. https://www.eia.gov/outlooks/aeo/.

Feldman, David, Vignesh Ramasamy, Ran Fu, Ashwin Ramdas, Jal Desai, and Robert Margolis. 2021. U.S. Solar Photovoltaic System and Energy Storage Cost Benchmark: Q1 2020. Golden, CO: National Renewable Energy Laboratory. NREL/TP-6A20-77324.

https://doi.org/10.2172/1764908. 


\section{References (continued)}

Feldman, David, Mark Bolinger, and Paul Schwabe. 2020. Current and Future Costs of Renewable Energy Project Finance Across Technologies. Golden, CO: National Renewable Energy Laboratory. NREL/TP-6A20-76881. https://www.nrel.gov/docs/fy20osti/76881.pdf.

James, Robert E., Dale Kearins, Marc Turner, Mark Woods, Norma Kuehn, and Alexander Zoelle. 2019. Cost and Performance Baseline for Fossil Energy Plants Volume 1: Bituminous Coal and Natural Gas to Electricity. National Energy Technology Laboratory. NETL-PUB-22638. https://doi.org/10.2172/1569246.

Mongird, Kendall, Vilayanur Viswanathan, Jan Alam, Charlie Vartanian, Vincent Sprenkle, and Richard Baxter. 2020. 2020 Grid Energy Storage Technology Cost and Performance Assessment. U.S. Department of Energy. DOE/PA-0204 . https://www.energy.gov/energy-storage-grandchallenge/downloads/2020-grid-energy-storage-technology-cost-and-performance.

O'Connor, Patrick W., Scott T. DeNeale, Dol Raj Chalise, Emma Centurion, and Abigail Maloof. 2015. Hydropower Baseline Cost Modeling, Version 2. Oak Ridge, TN: Oak Ridge National Laboratory. ORNL/TM-2015/471. https://doi.org/10.2172/1244193.

Oladosu, Gbadebo, Lindsay George, and Jeremy Wells. 2021. 2020 Cost Analysis of Hydropower Options at Non-Powered Dams. Oak Ridge, TN: Oak Ridge National Laboratory. ORNL/TM-2020/1656. https://doi.org/10.2172/1770649.

Stehly, Tyler, Philipp Beiter, and Patrick Duffy. 2020. 2019 Cost of Wind Energy Review. Golden, CO: National Renewable Energy Laboratory NREL/TP-5000-78471. https://doi.org/10.2172/1756710.

Turchi, Craig, Matthew Boyd, Devon Kesseli, Parthiv Kurup, Mark Mehos, Ty Neises, Prashant Sharan, Michael Wagner, and Timothy Wendelin. 2019. CSP Systems Analysis: Final Project Report. Golden, CO: National Renewable Energy Laboratory. NREL/TP-550072856. https://doi.org/10.2172/1513197. 


\section{Acronyms and Abbreviations}

Annual Energy Outlook

application programming interface

Annual Technology Baseline

Amazon Web Services-Simple Storage Service

business as usual

capital expenditures

combustion turbine

carbon capture and storage

concentrating solar power

comma-separated values

U.S. Department of Energy

debt service coverage ratio

U.S. Department of Energy Office of Energy Efficiency and Renewable Energy

enhanced geothermal systems

U.S. Energy Information Administration

DOE Office of Fossil Energy

Geothermal Electricity Technology Evaluation Model

integrated gasification combined cycle

independent power producer

levelized cost of energy

natural gas combined cycle

non-powered dam

National Renewable Energy Laboratory

new stream-reach development

Oak Ridge National Laboratory

power purchase agreement

Regional Energy Deployment System Model

System Advisor Model

supercritical pulverized coal 